\title{
Population and development: An introductory view [Arabic]
}

Geoffrey McNicoll

Population Council

Follow this and additional works at: https://knowledgecommons.popcouncil.org/departments_sbsr-pgy

Part of the Demography, Population, and Ecology Commons, Family, Life Course, and Society Commons, and the International Public Health Commons How does access to this work benefit you? Let us know!

\section{Recommended Citation}

McNicoll, Geoffrey. 2003. "Population and development: An introductory view," Policy Research Division Working Paper no. 174 [Arabic]. New York: Population Council. 


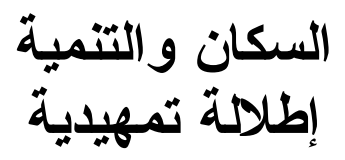

إعداد جوفري ماكنيكول

Geoffrey McNicoll

IV $V$ ع r.. r

مجلس السكان

جوفري ماكنيكول شريك أول، مجلس السكان، نيويورك.

يستند هذا العرض الملخص إلى المادة التي تم إعدادها للمقالين المعدين للنشر في موسوعتين كالآتى:

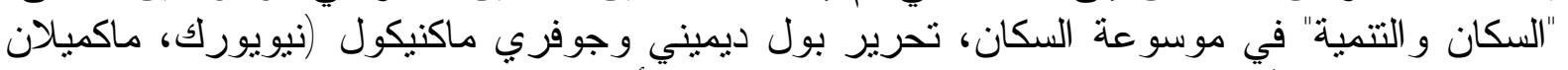

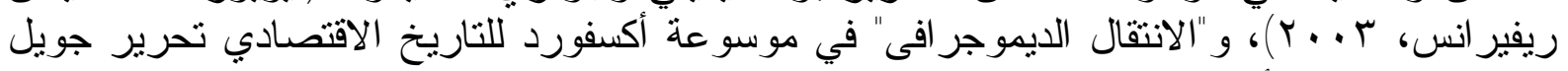
موكير (نيويورك، أكسفورد يونيفرسيتي بريس، تحت الطبه الطبع) 
تقدم هذه الورقة نظرة عامة مختصرة حول العلاقة بين التغيير ات السكانية و النمو الاقتصادي؛ وهي ولقي

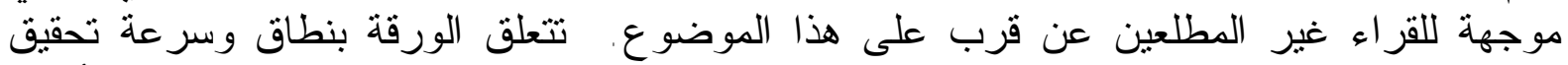

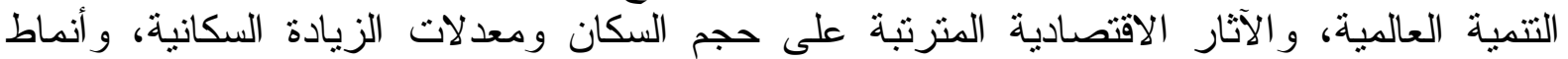

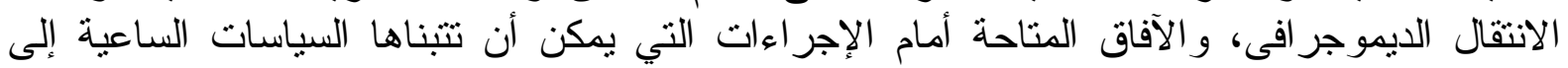

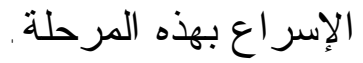

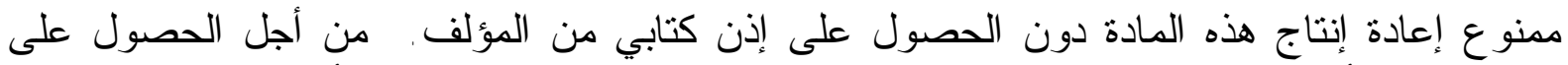

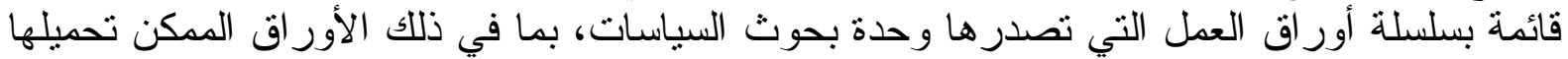

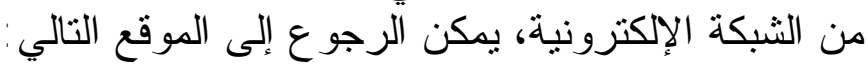
www.popcouncil.org/publications/wp/prd/rdwplist.html

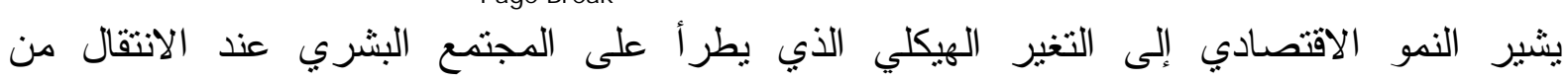

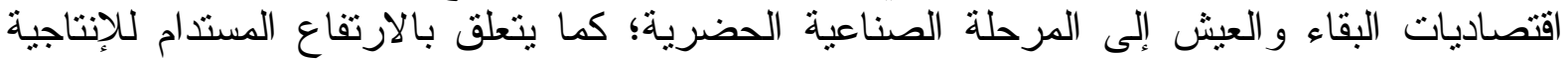

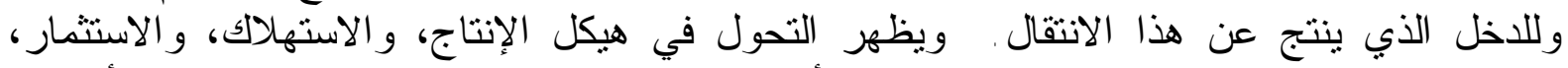

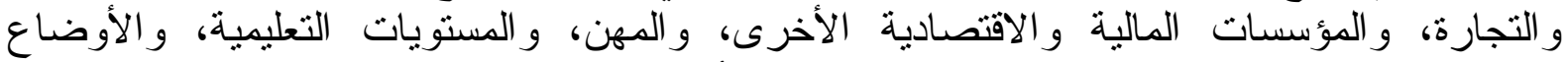

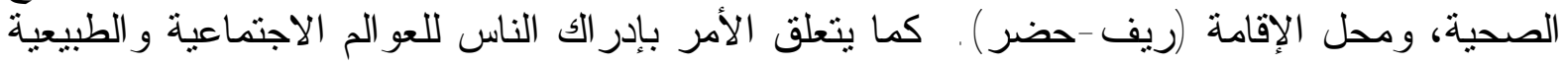

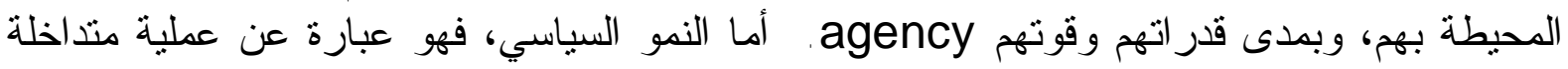




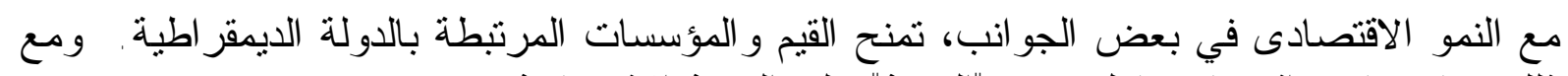
ذلك، عادة ما يتم اقتصار تتاول تعبير "التتمينة" على التنمية الاقتصادية.

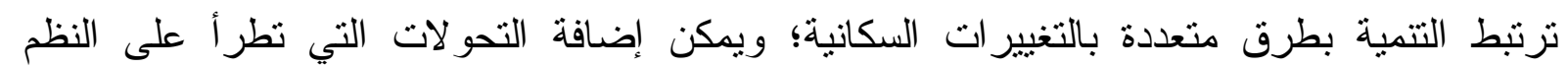

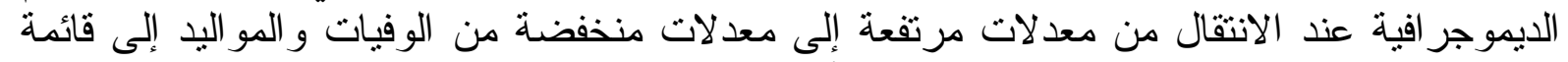

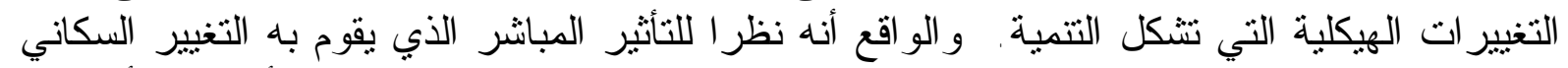

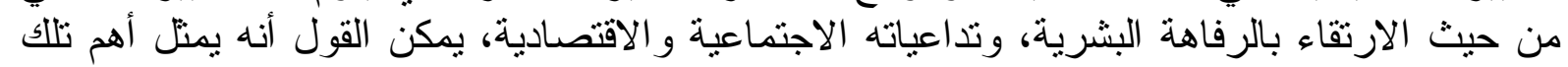

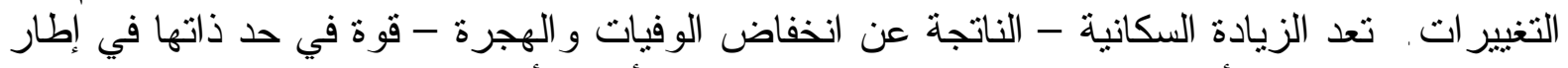

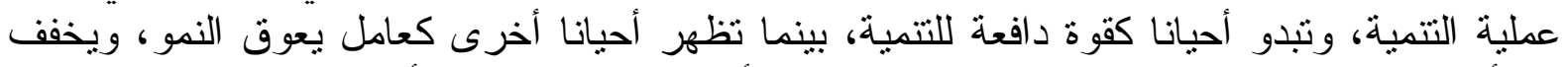

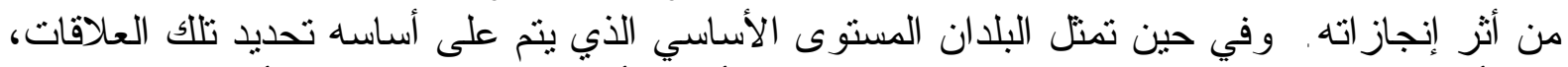

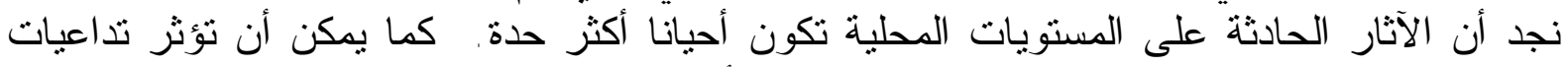

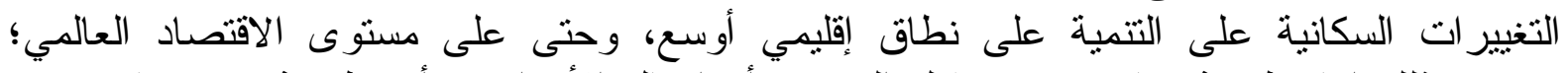

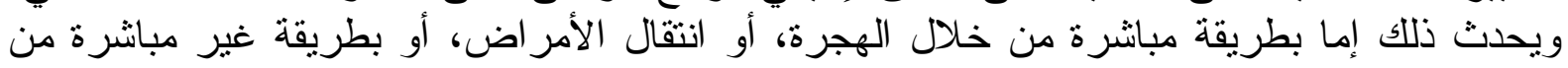

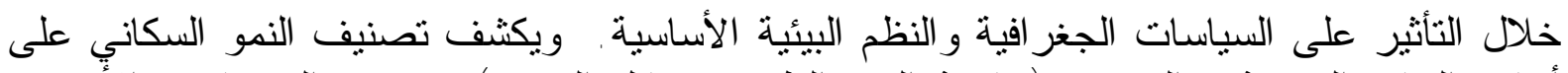

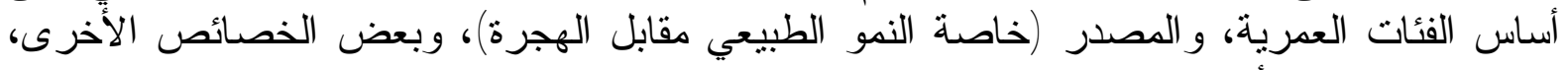

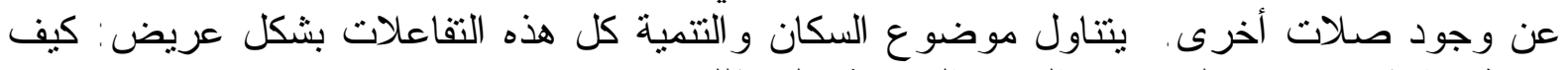
تصطدم الاقتصاديات بالسكان، و النتائج المترنبة على ذلان ولك .

\section{حجم وسرعة التنمية}

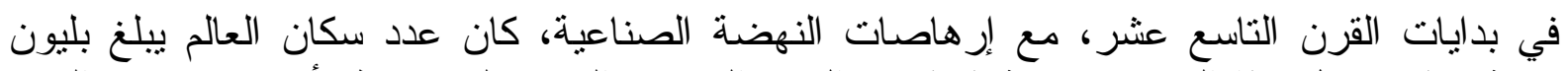

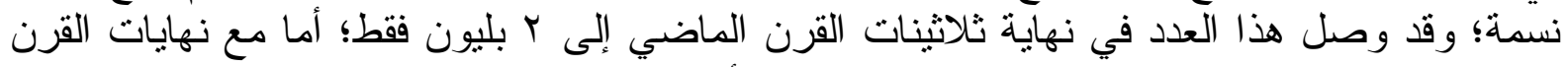

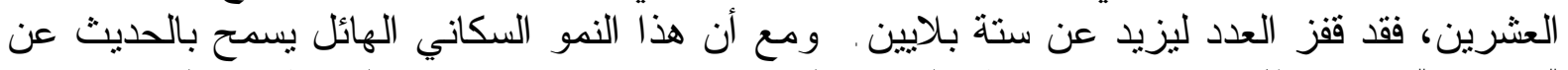

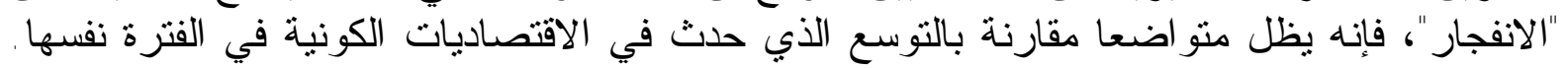

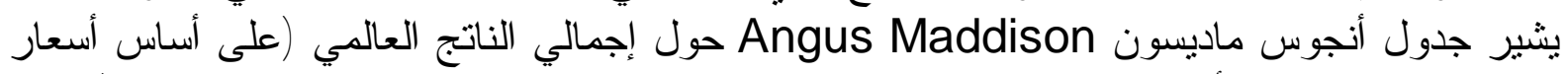

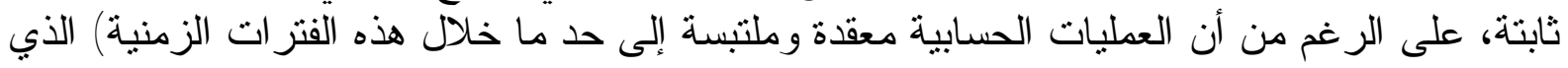

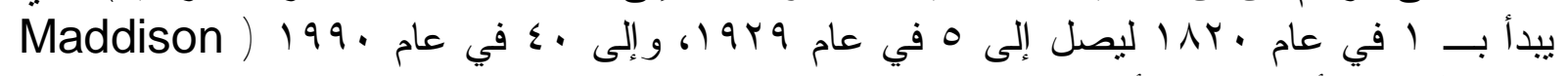

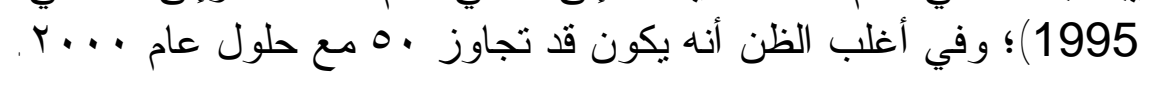

اتسم هذا النمو بعدم الانتظام على مستوبين؛ فقد نمى السكان بطريقة ملفتة للنظر في أوروبا وأمريكا

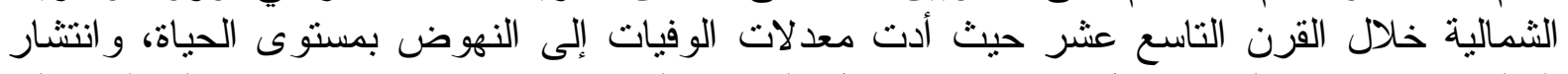

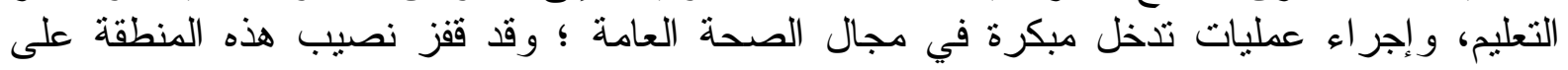

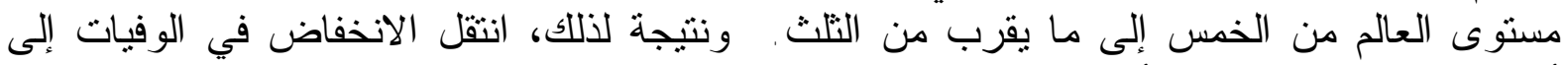

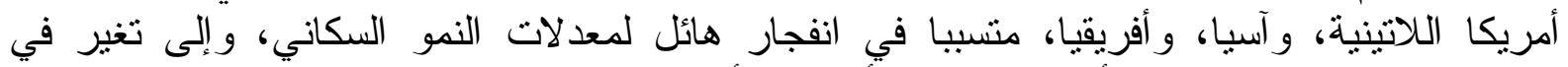

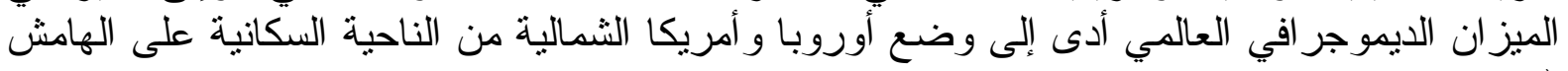

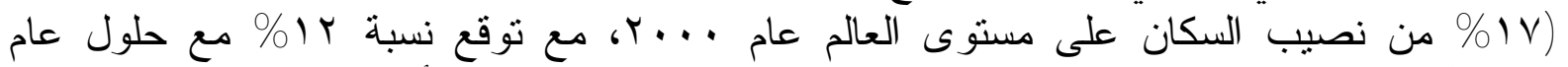

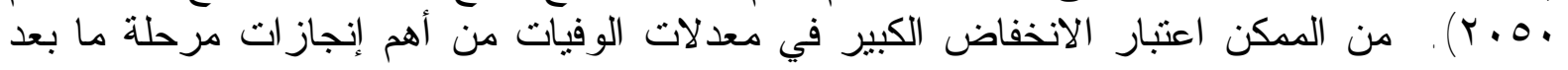

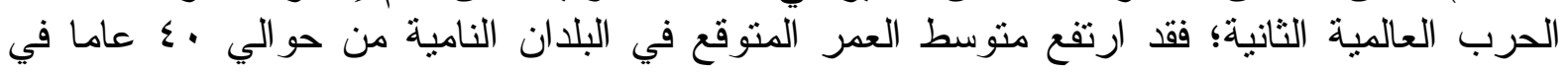

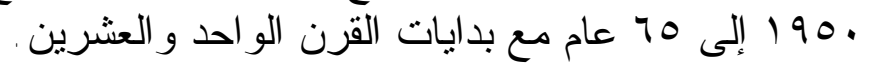

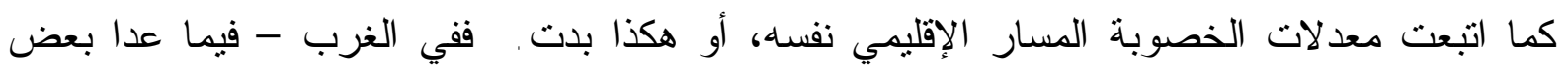

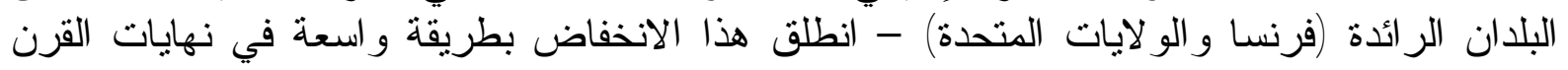


التاسع عشر وبدايات القرن العشرين، و انتقل إلى العالم غير الصناعي بعد الحرب العالمية الثانية؛ غير

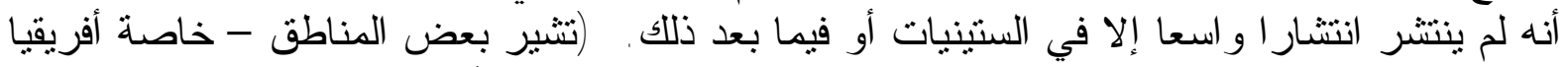
تحت الصحر اء - إلى وجود انخفاض ضئيل في نهايات القرن العشرين) التئي

يوضح شكل ا المعدلات التقديرية للولادات و الوفيات خلال فترة الانتقال الديموجر افى في ثلاث

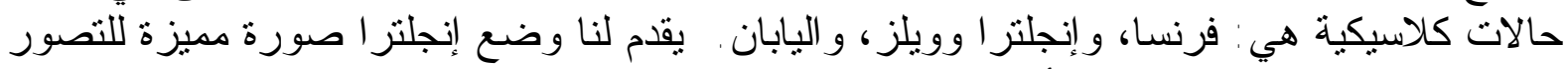

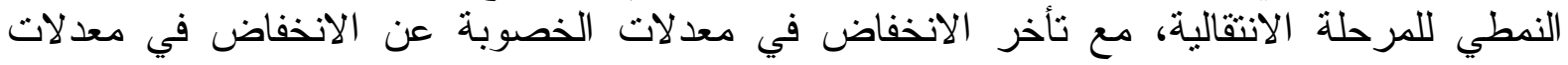

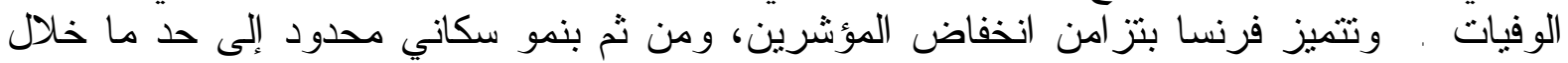
هذه المرحلة.

تبرز صورة المو اقع الإقليمية المنهادية في مجال الانتقال الديموجر افي على نطاق العالم وجود درجة

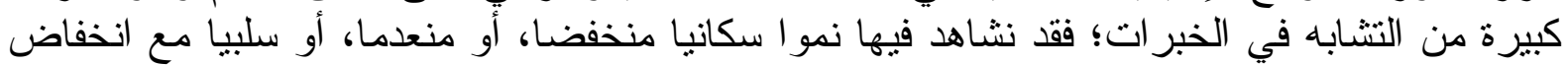

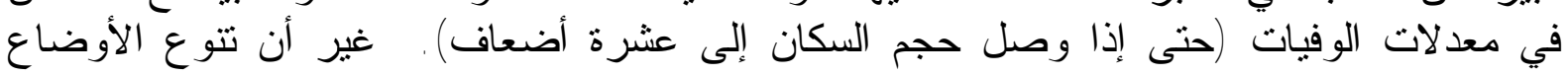

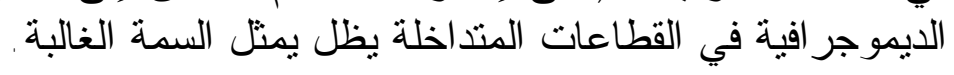

شكل أ: المعدلات السنوية للو لادات والوفيات لكل ...1 من السكان خلال المرحلة الانتقالية الديموجر افية فى فرنسا، و إنجلتر اوويلز ، واليابان 


\section{FIGURE 1}
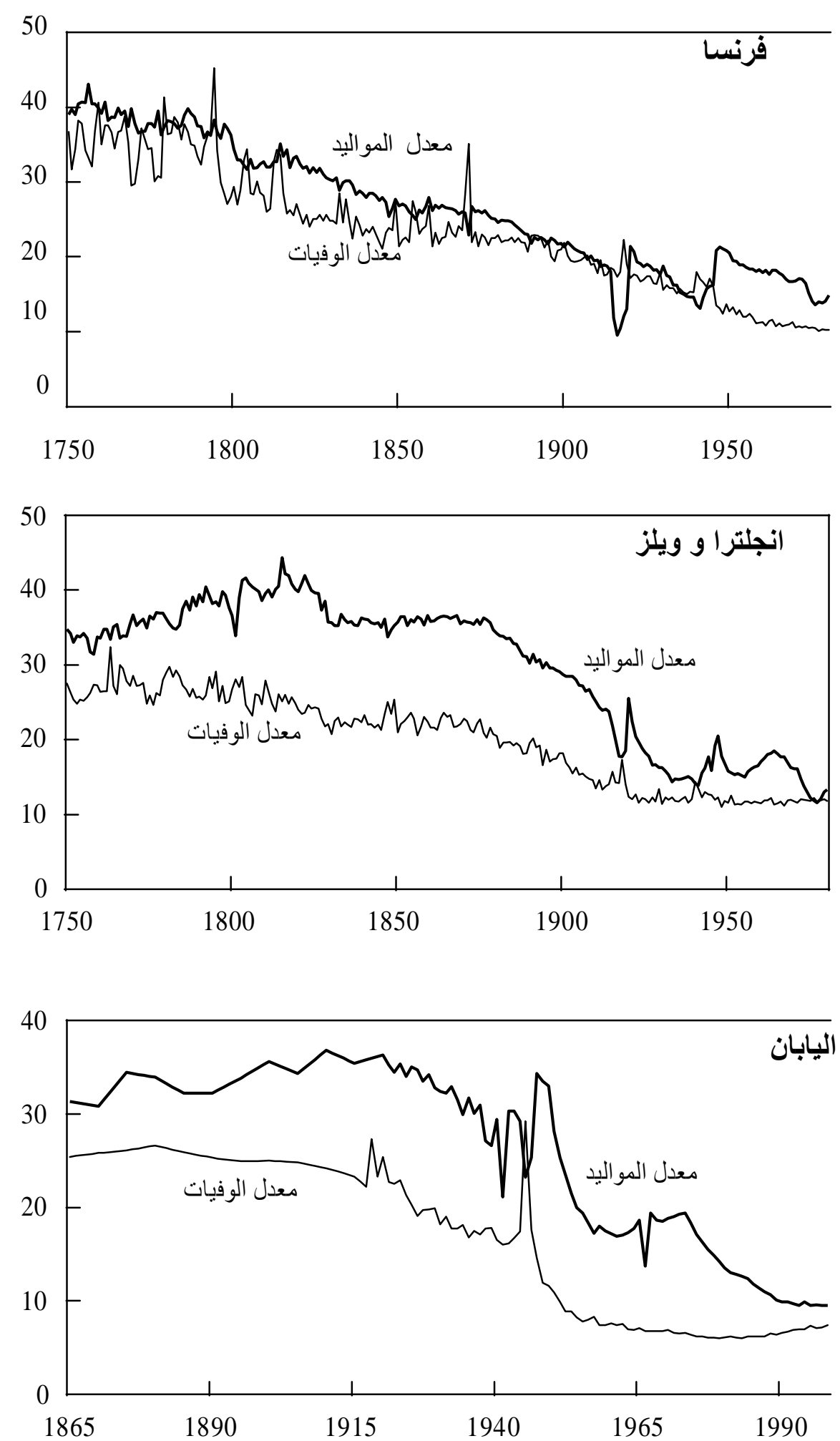

ملحوظة: تشير التقدير ات السابقة لعام • ب 19 بالنسبة لليابان الى متوسطات خمس سنوات مصدر البيانات: Chesnais (1986), Wrigley and Schofield (1981), Ohbuchi and United Nations Yearbook 
في العقود التالية للحرب العالمية الثانية، شهدت البلدان التي ترتفع فيها معدلات الوفيات و الخصوبة

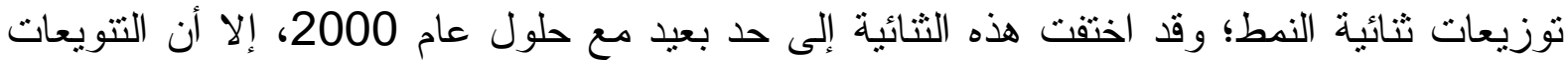
التى تعكس المسافة بين البلدان الر ائدة و البلدان المتقاعسة خلال المرحلة الانتقالية ظلت و اسعة .

وبدا وكأن النمو الاقتصادي قد نم تصوره بشكل واضح من خلال عملية شبيهة بحيث تصل البلدان

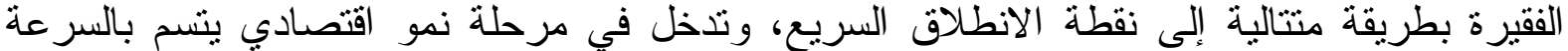

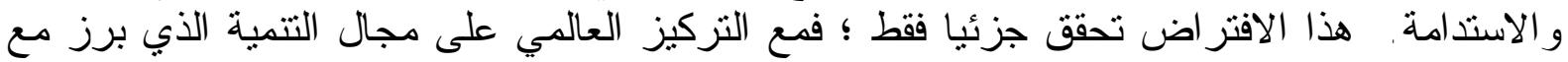

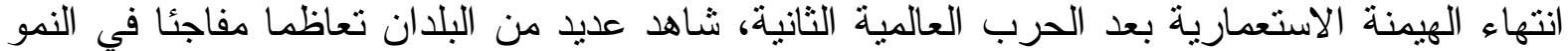

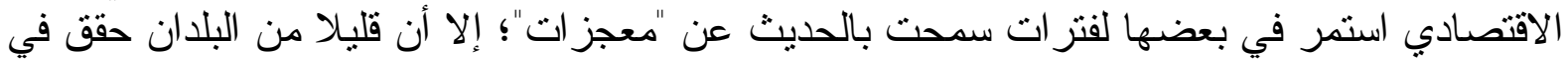

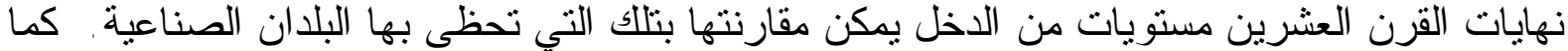

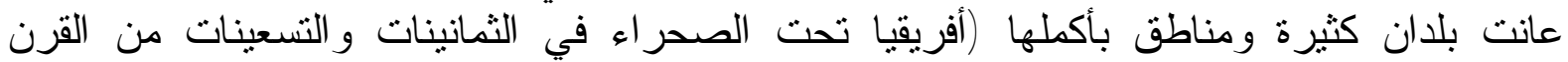

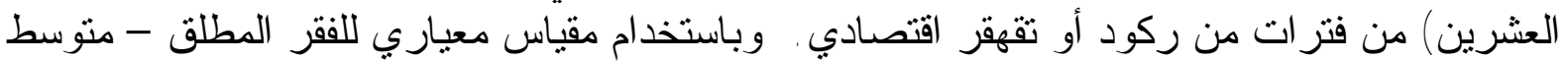

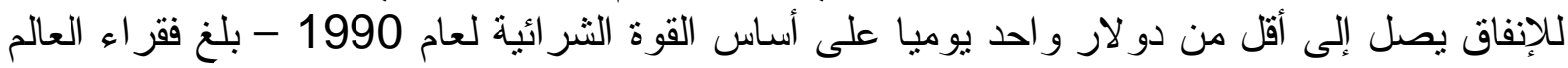
ما يقرب من 1.2 بليون شخص (أي 20\% من سكان العالم) في نهاية التسعينات.

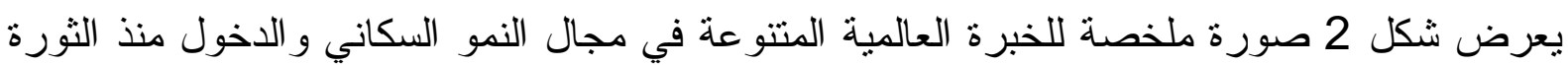

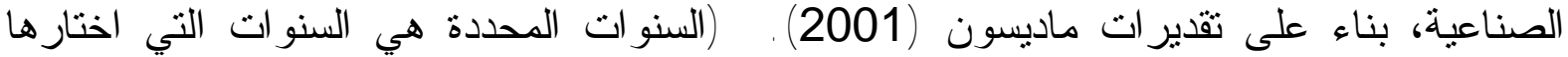

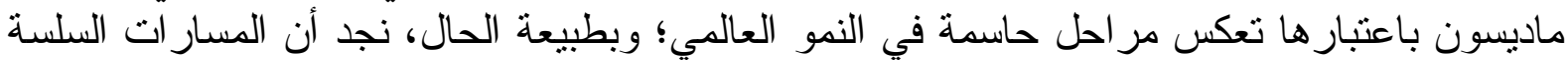

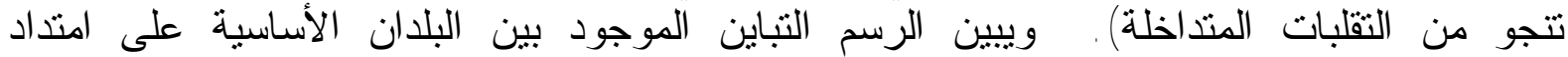

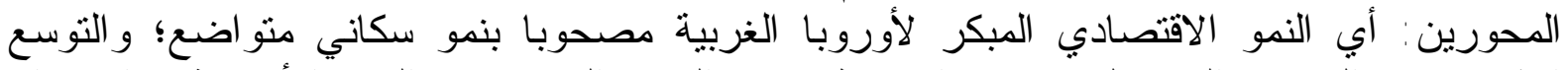

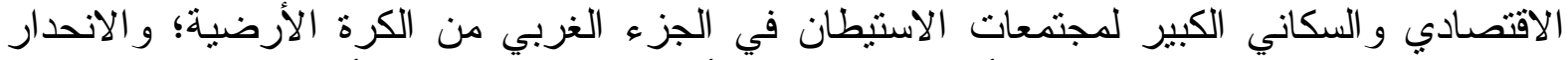

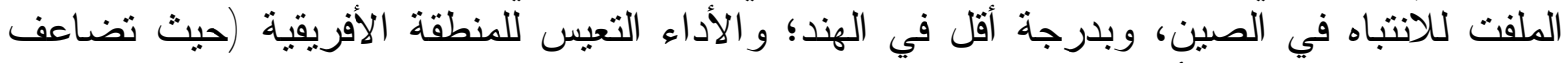

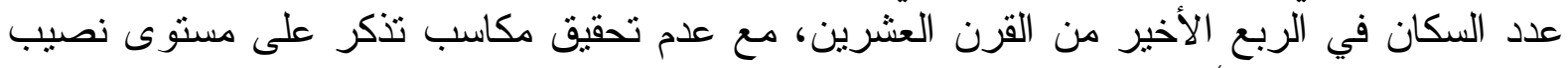

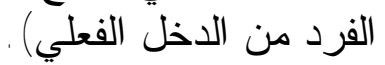

\section{حجم السكان والتنمية}

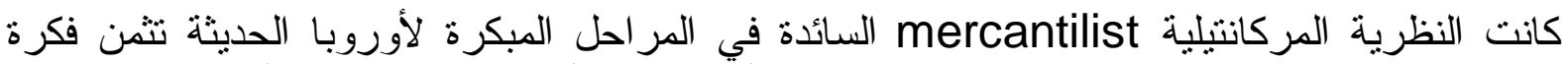

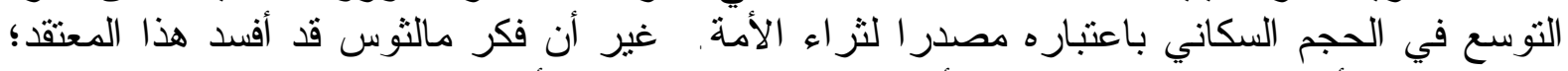

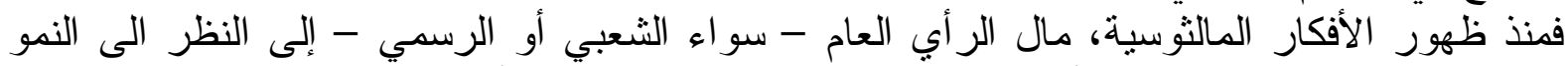

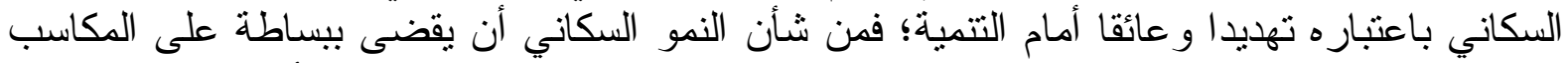

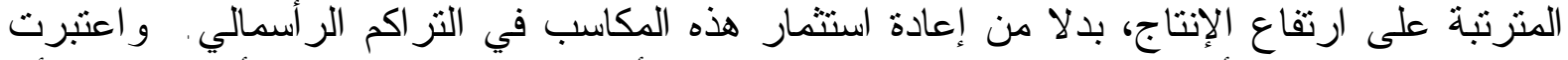

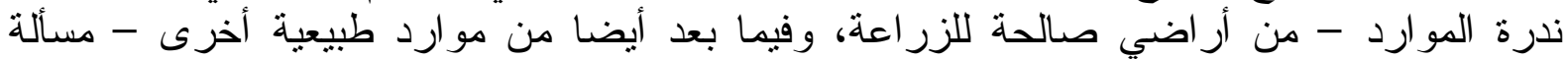

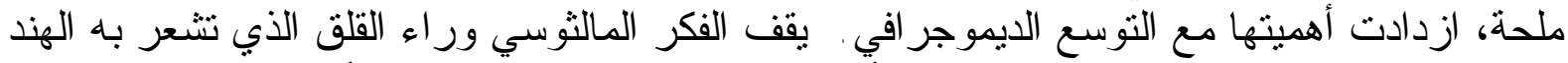

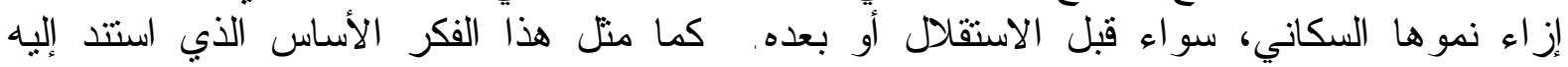

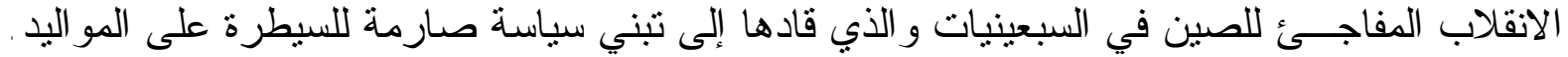

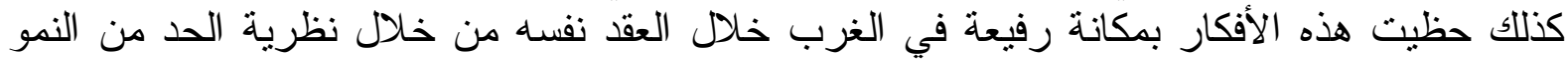
التي اقترحها المدافعون عن البيئة.

شكل 2: مسار ات السكان و إجمالي نصيب الفرد من الناتج المحلي في بلدان ومناطق المختارة، 1820 -1998 


\section{FIGURE 2}

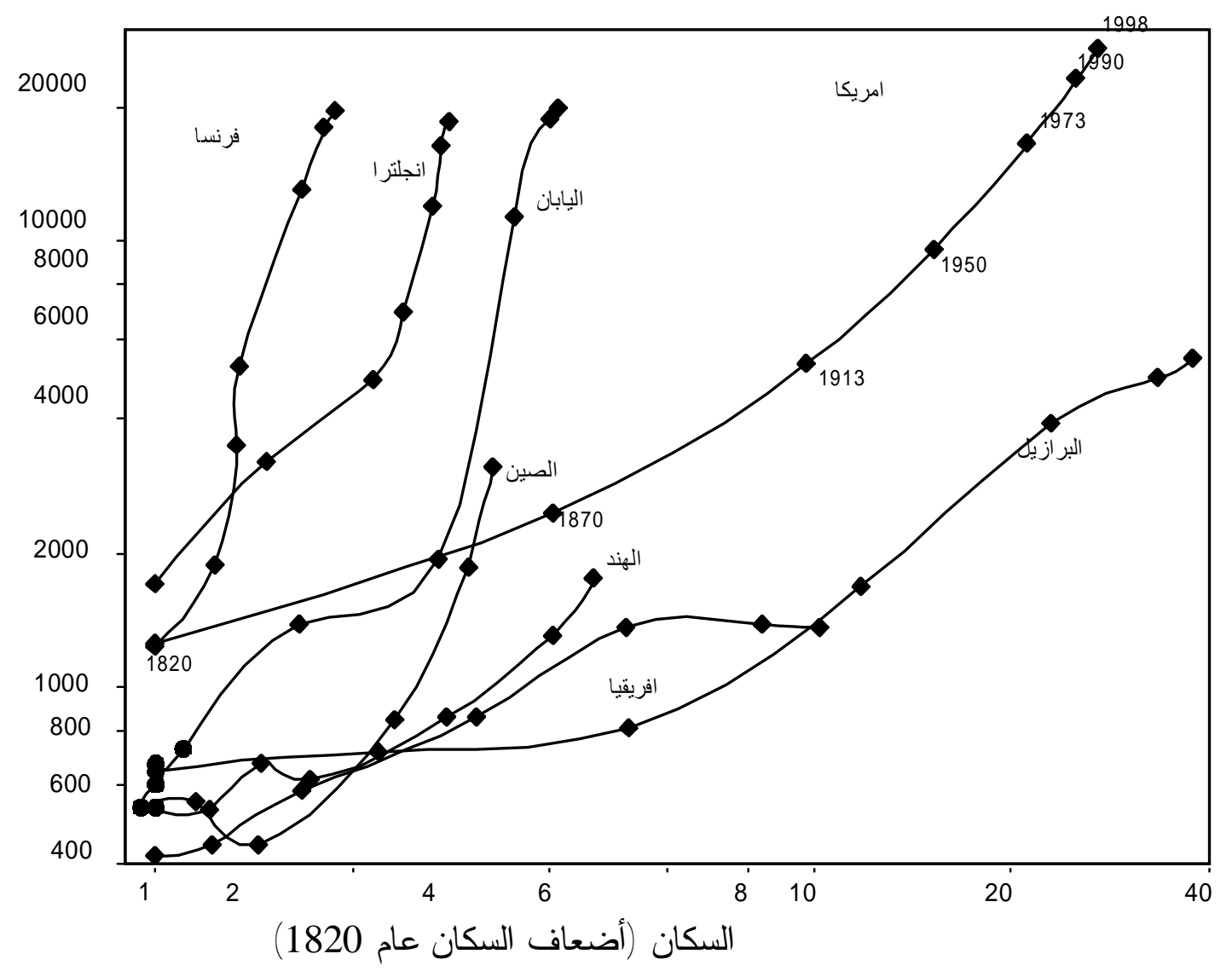

ملحوظة: الدخل على أساس القوة

الثرائية للدولار في عام 1990.

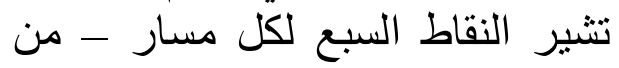

اليسار إلى اليمين - إلى الوضى الوضع في

أعوام 1820، 1873، 1870، 1913، 1990،

1950، 1973، 1990، 1998.

3-مصدر البيانات: Maddison

(2001), Appendix A. 
كما قام الفكر المالثوسي بدور أكثر تتوعا في مجال علم الاقتصاد. فقد انخفض الاعتماد على الموارد

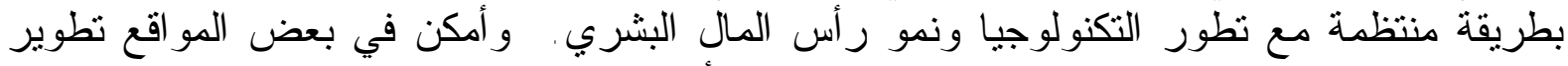

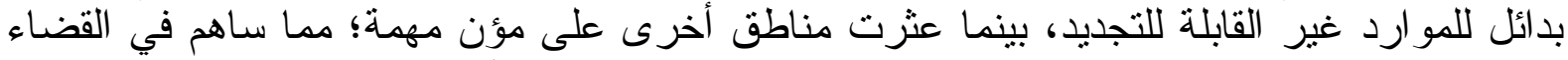

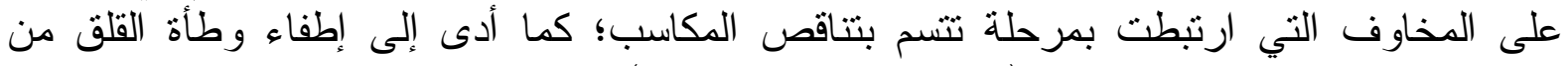

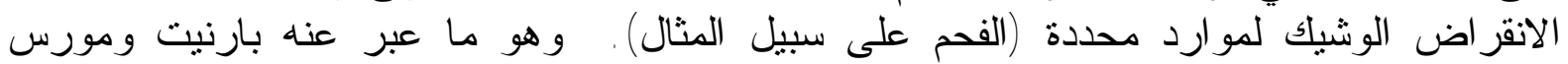
Barnett and Morse

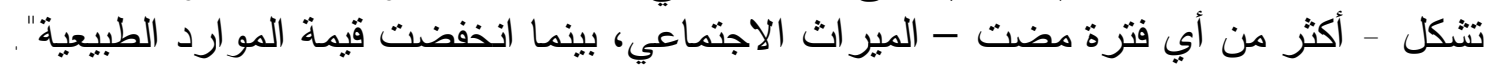

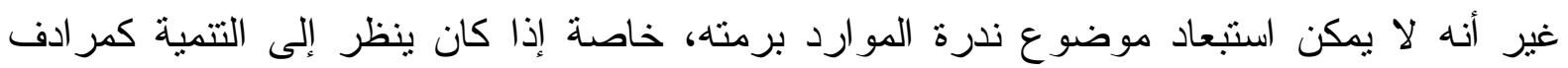

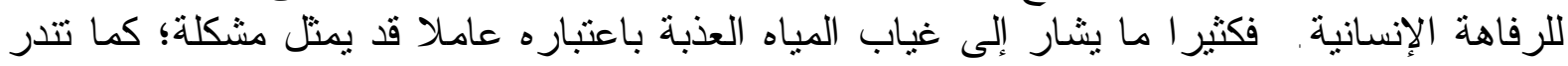

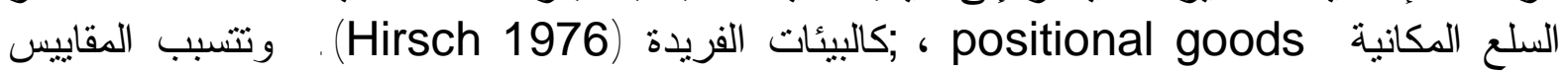

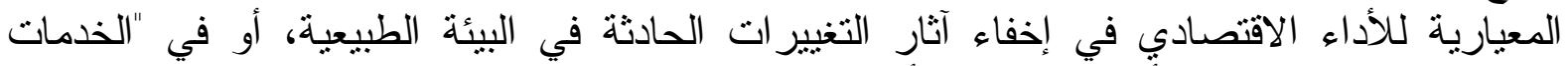

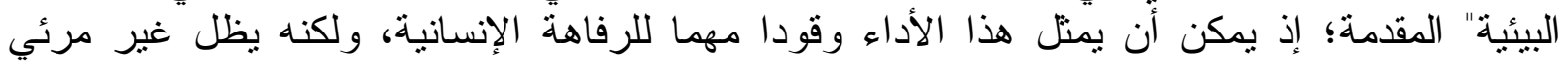

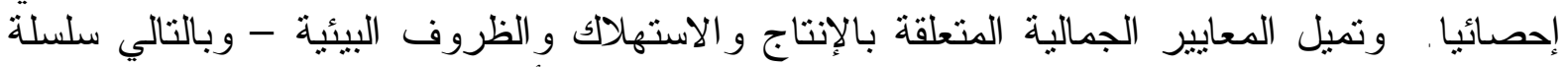
و اسعة من الصفات المميزة - إلى التعرض للإهمال حينما يتعلق الأمر بالقياس.

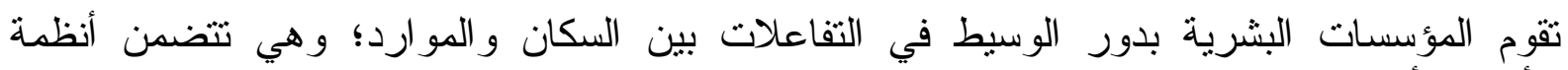

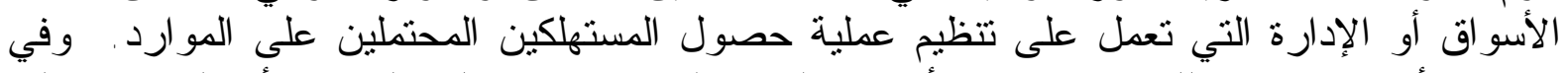

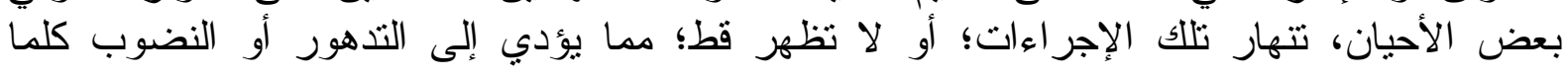

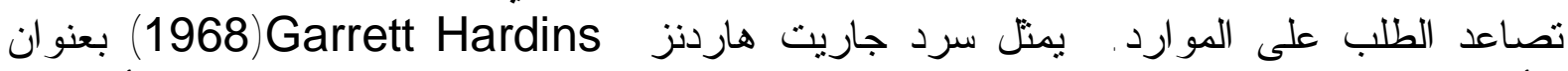

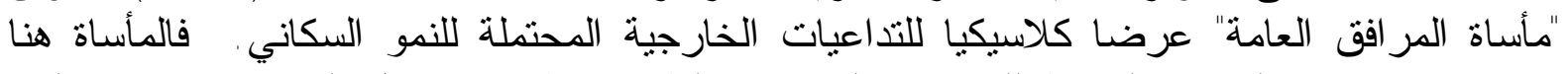

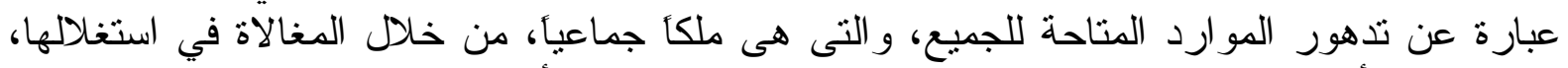

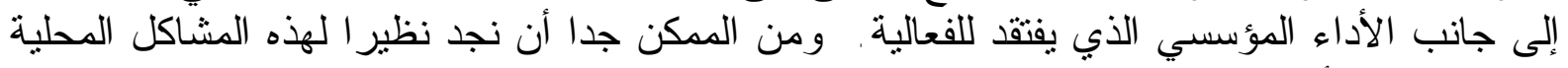

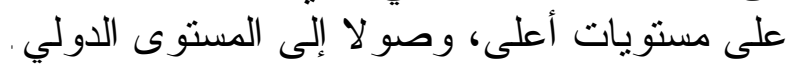

\section{النمو السكاني والتنمية}

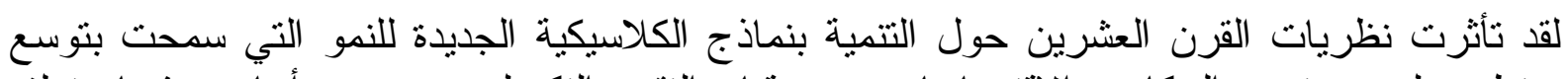

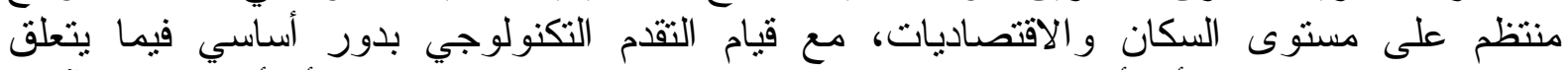

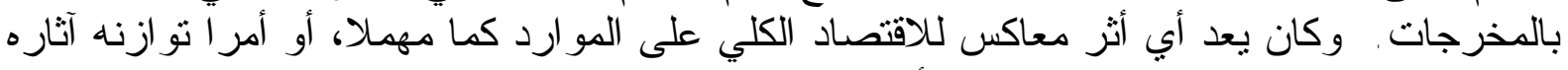

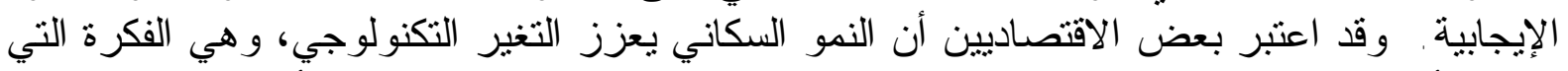

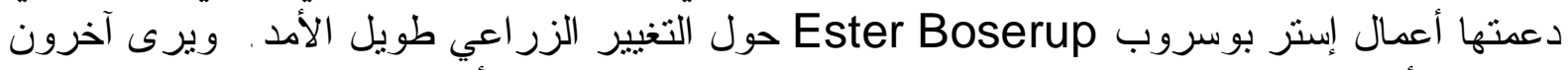

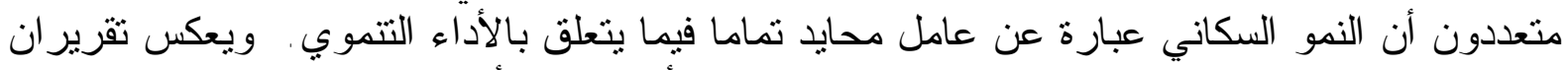

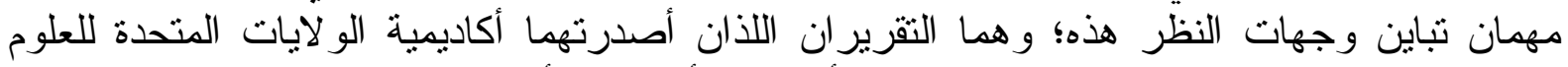

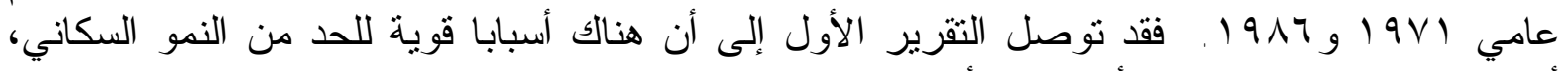

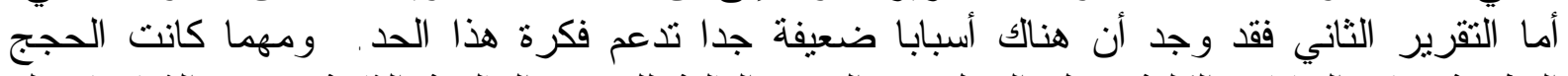

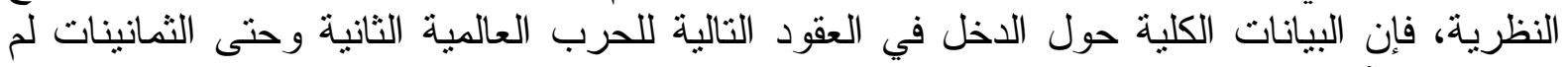

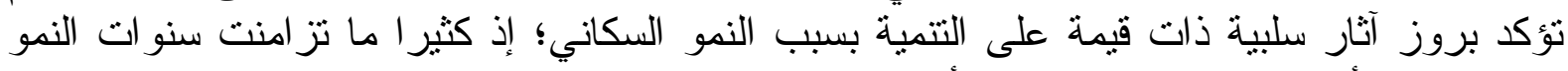
الاقتصادي الأسرع مع النمو السكاني الأسرع على على المسنوى القطري. 


\section{تأثير انخفاض معدلات الوفيات والخصوبة}

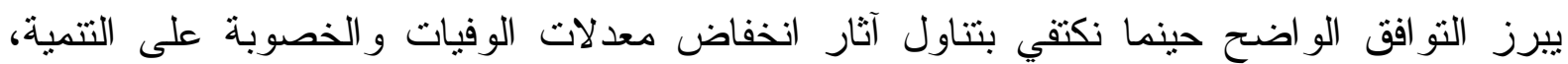

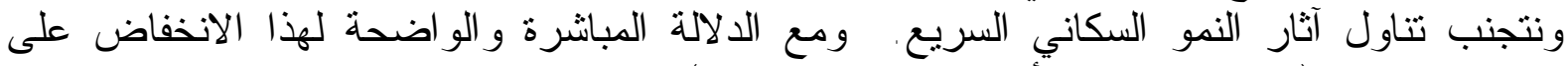

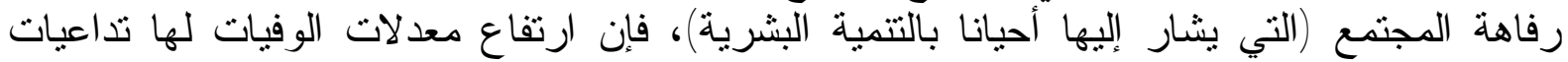

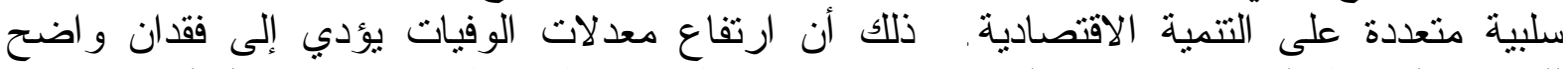

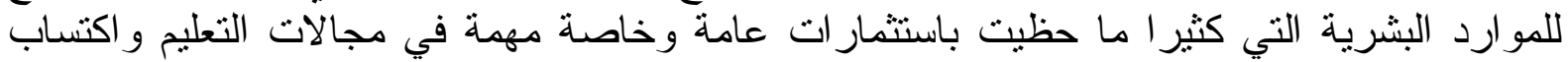

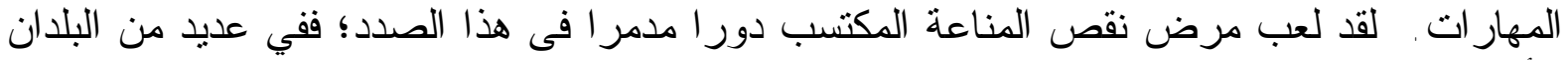

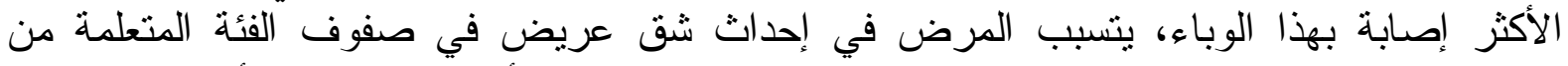

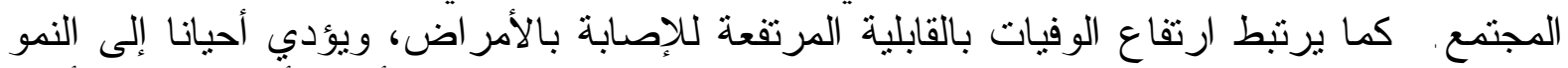

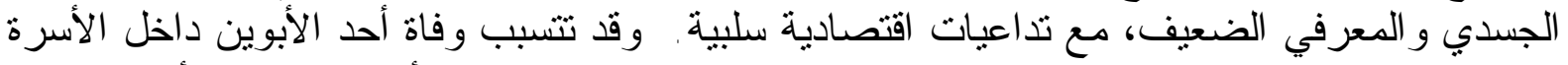

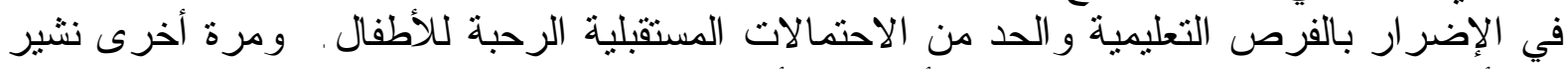

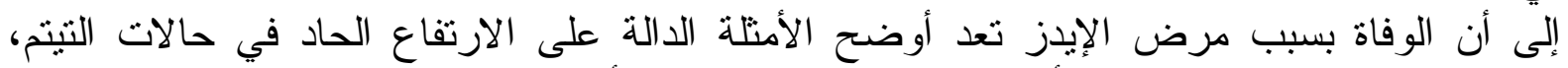

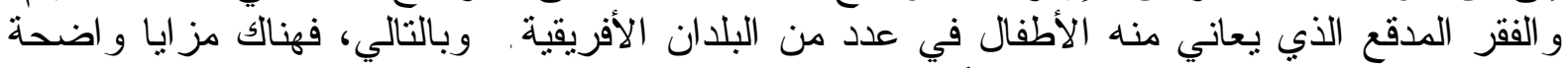

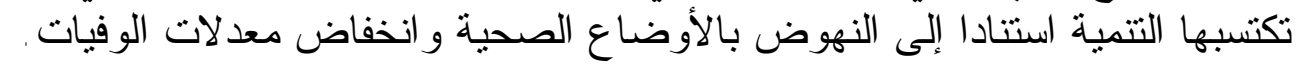

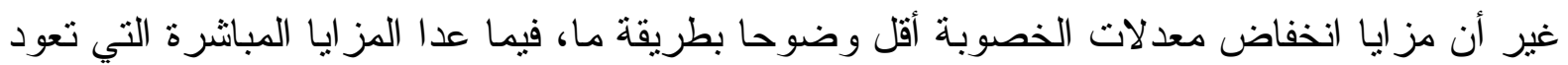

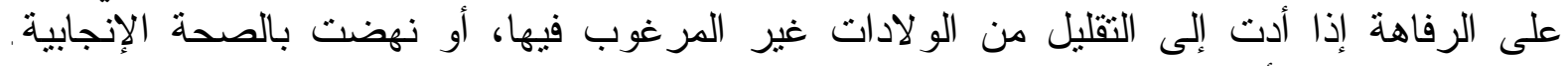

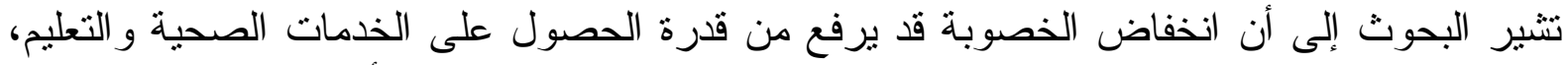

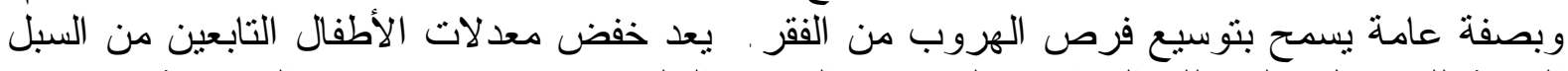

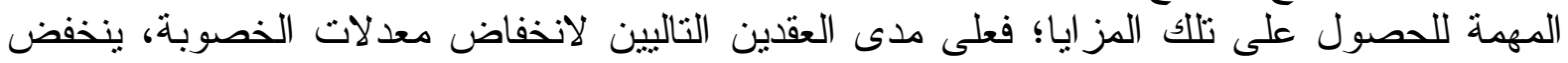

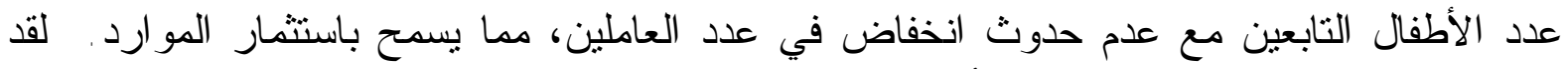

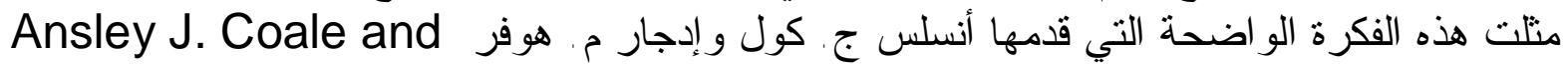
Edgar M. Hoover

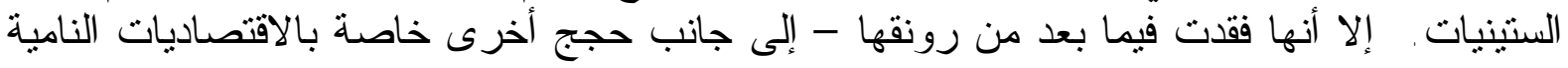

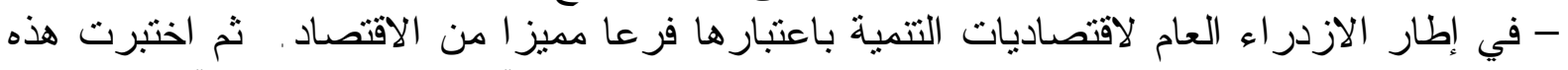

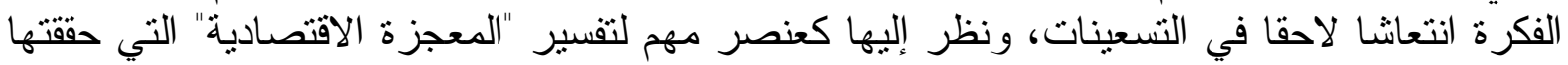

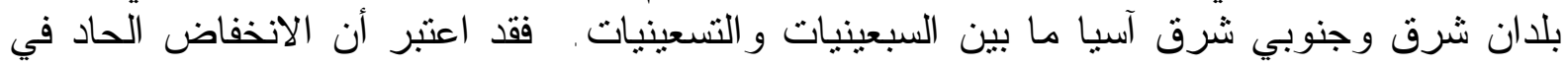

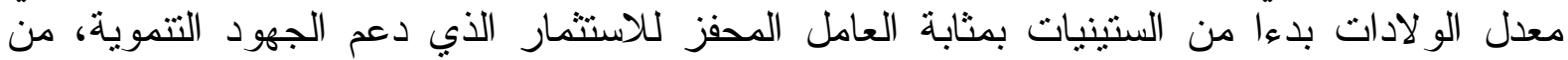

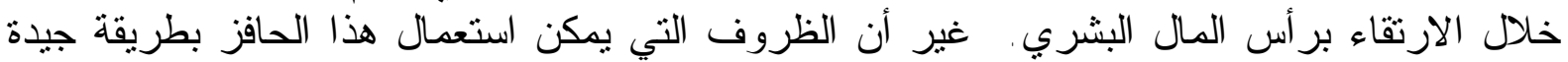

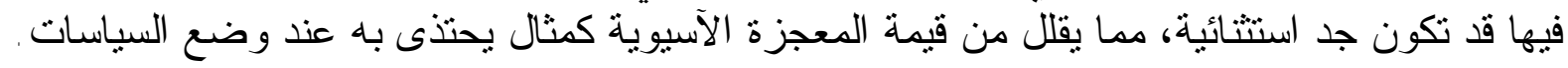

آثار التنمية

تتتاول "نظرية" المرحلة الديموجر افية الانتقالية آثار النمو الاقتصادي على ارتفاع الوفيات والخصوبة؛

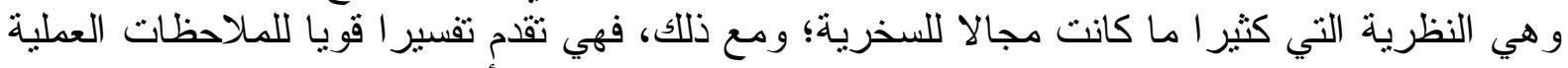

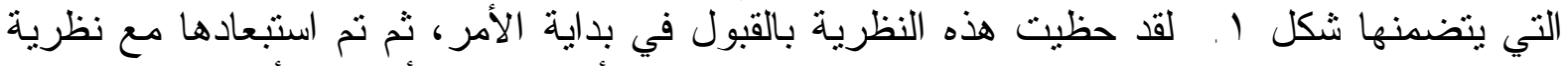

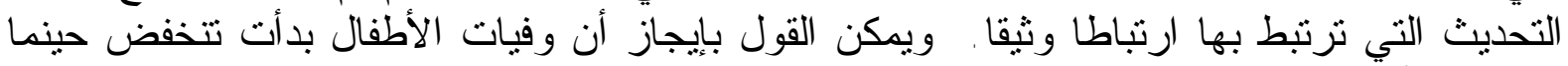

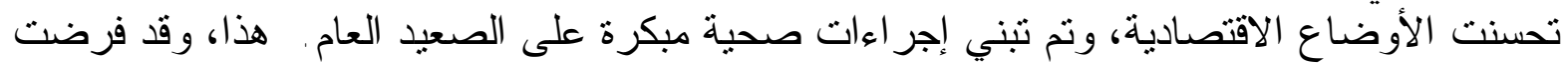




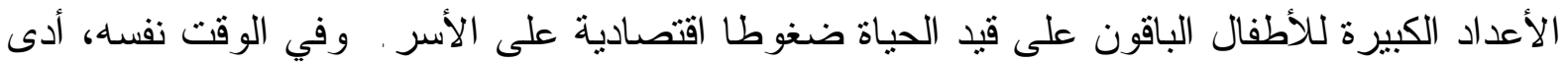

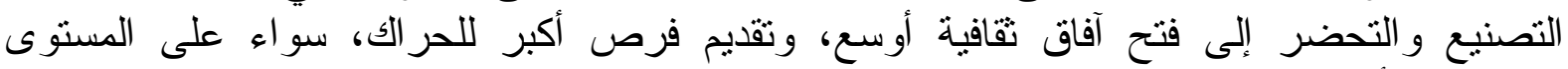

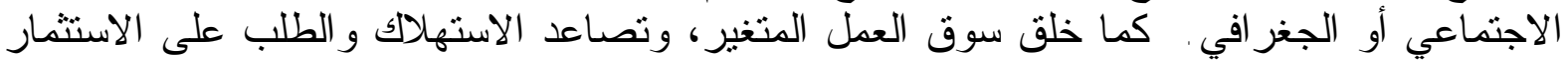

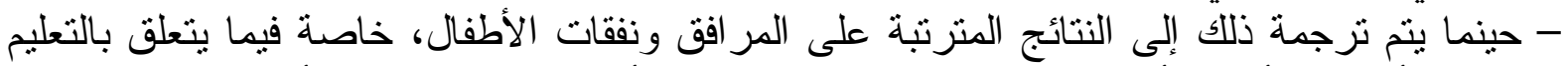

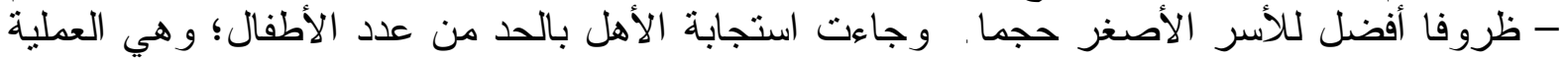

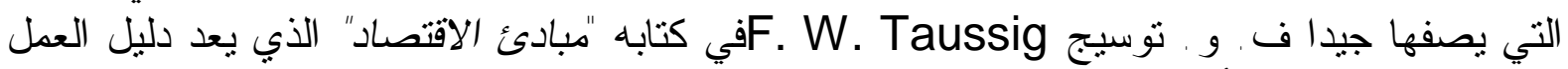
النموذجي للاقتصاد الأمريكي في بدايات القرن العشرين.

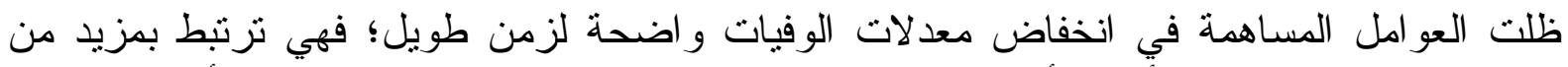

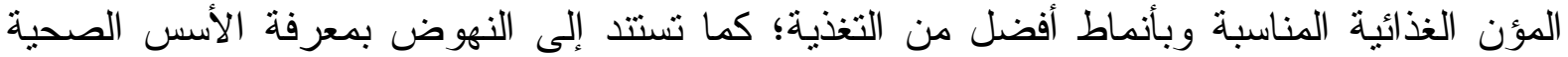

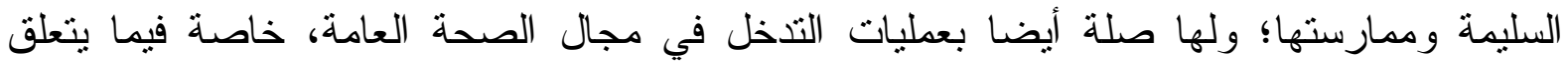

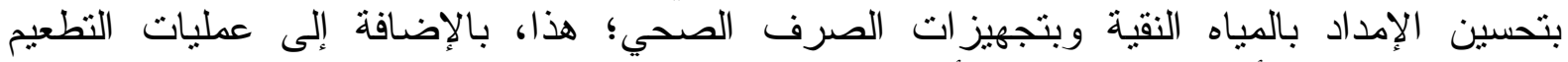

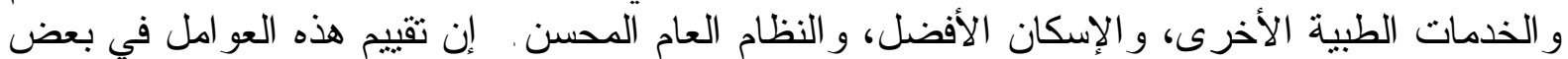

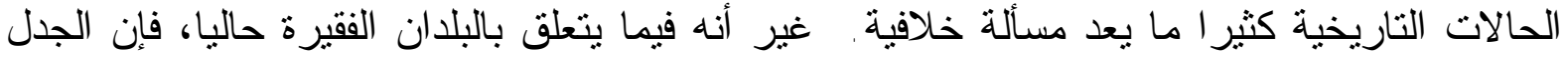

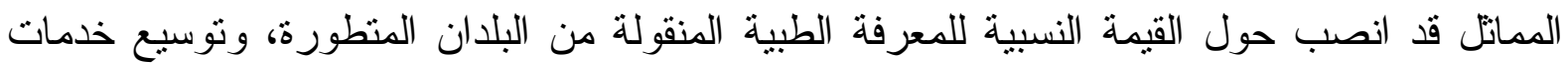

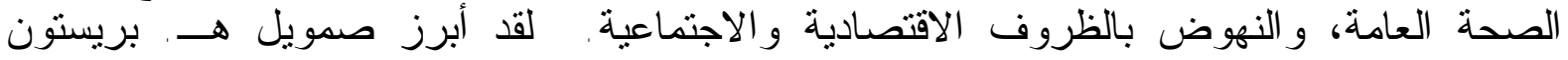
كالت

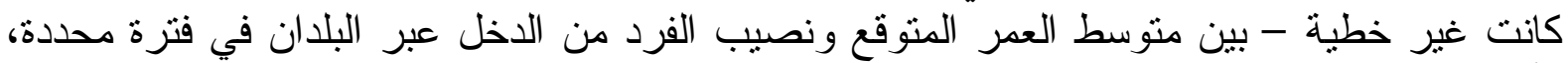

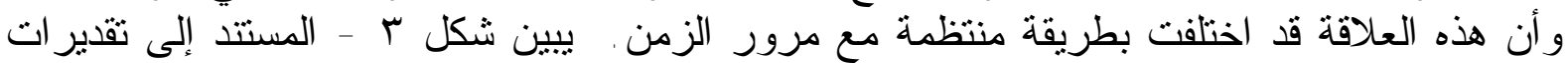

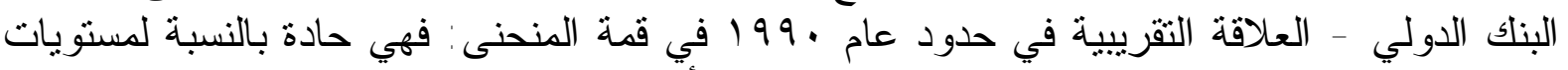

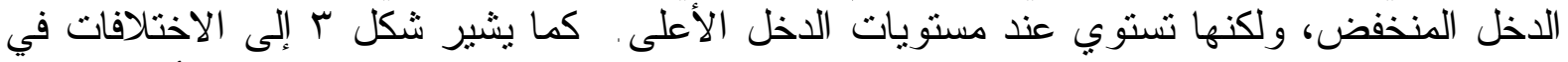

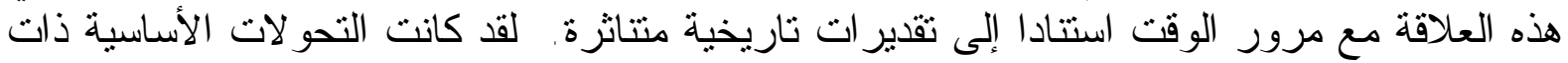

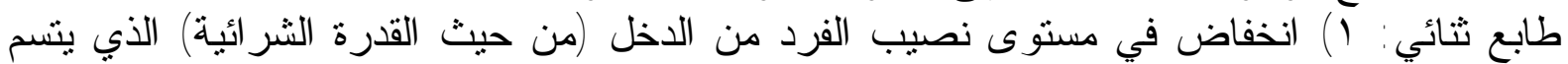

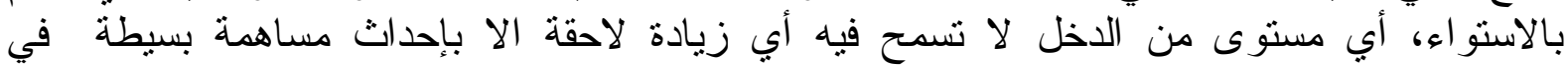

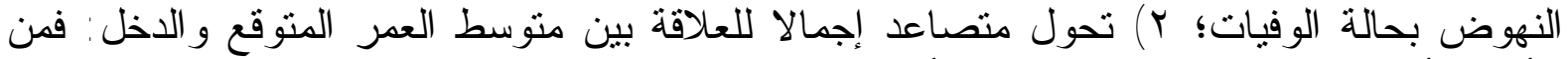

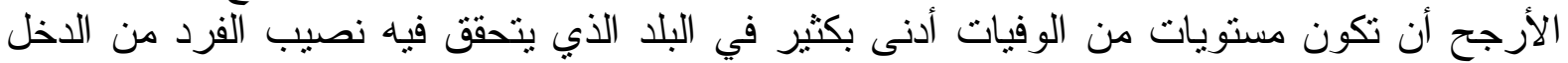
الفعلي اليوم مقارنة بالبلا الذي حقق مستوى الدخل نفسه منذ بضعة الذئ عقود سابقة . 


\section{FIGURE 3}

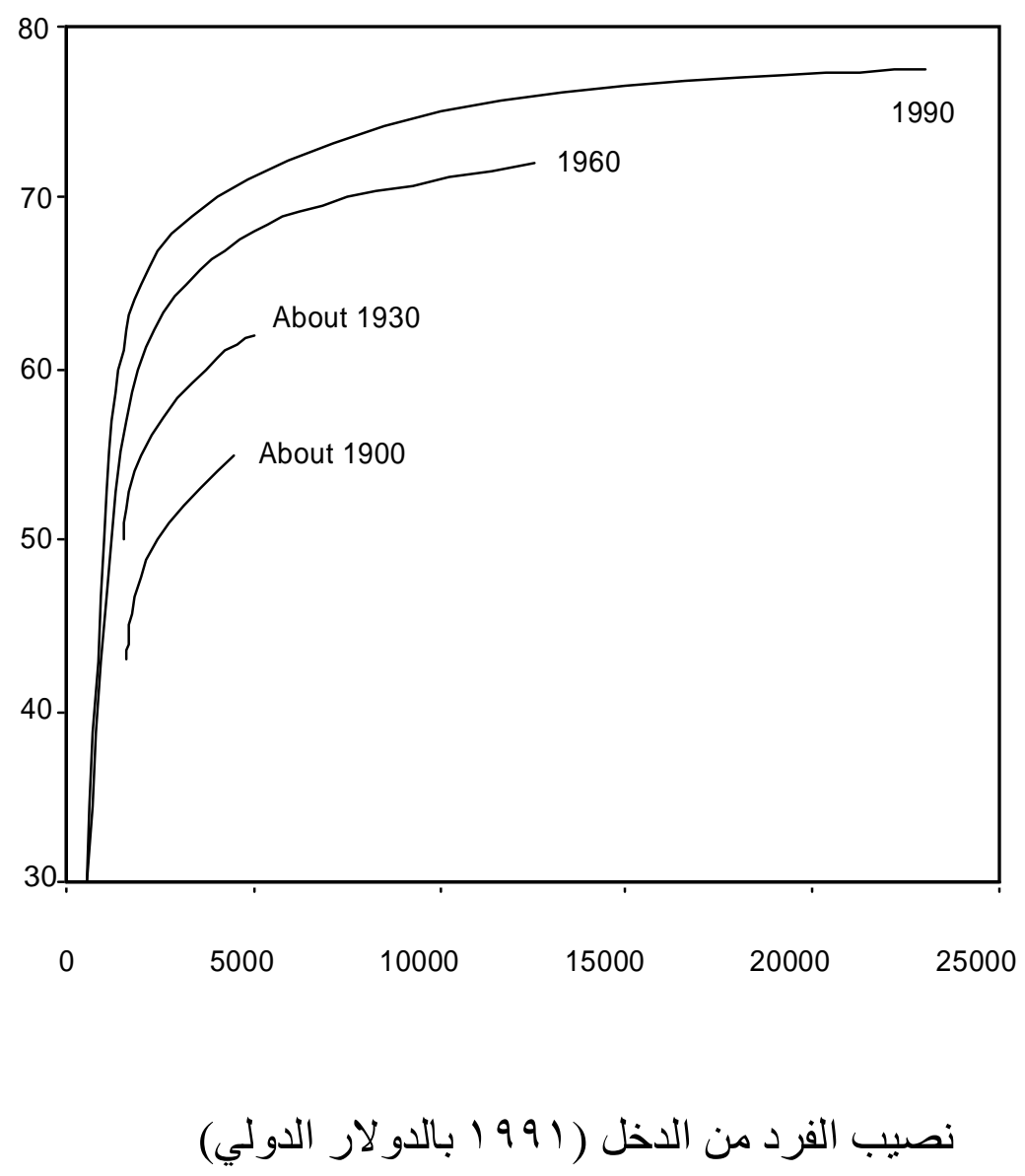

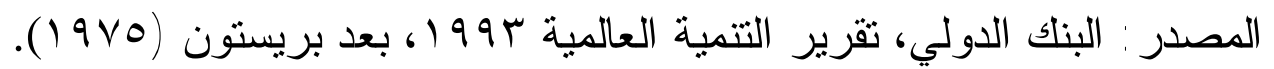
World Bank, World Development Report 1993, after Preston 


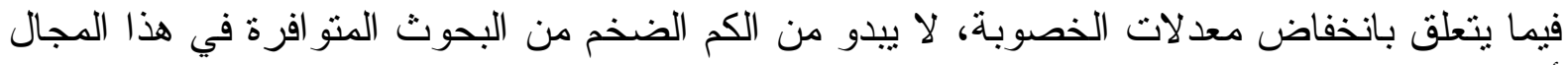

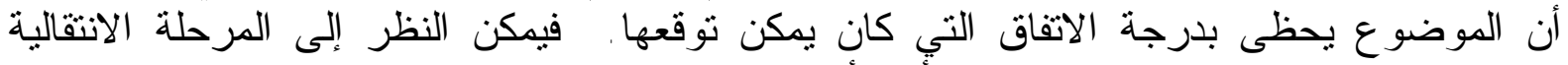

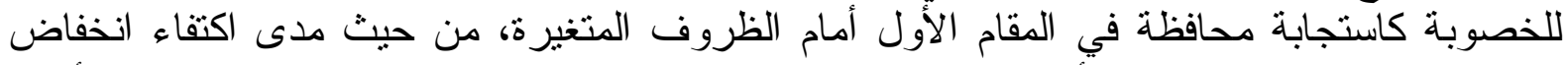

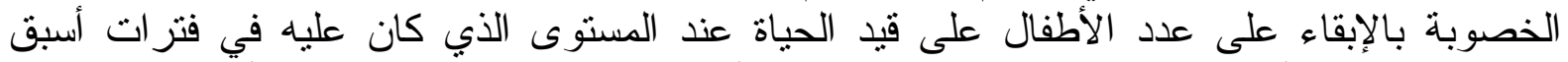

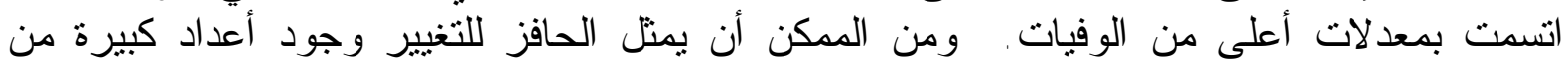

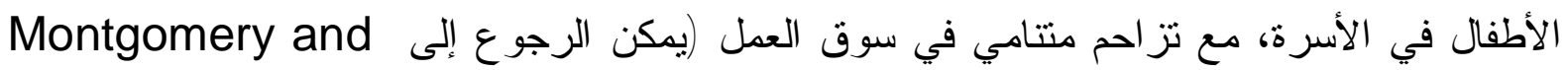

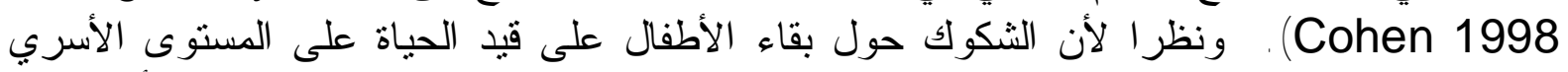

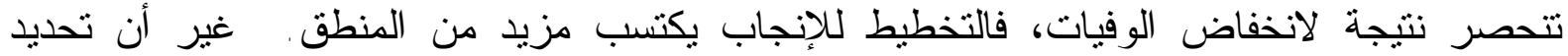

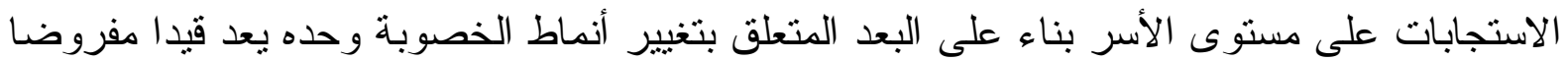

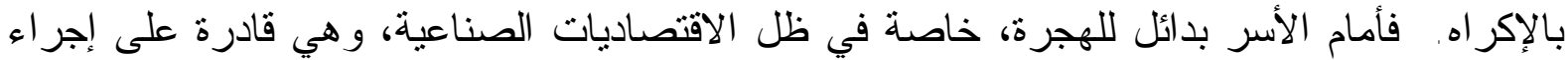

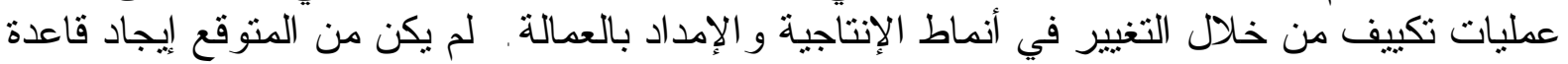
بسيطة في مجال تحول الخصوبة.

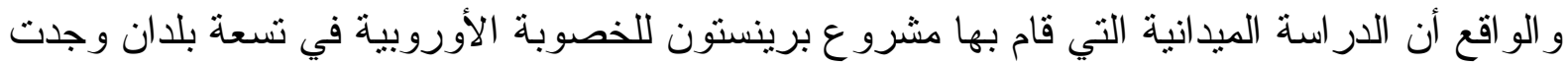

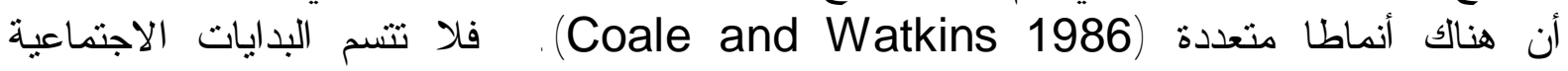

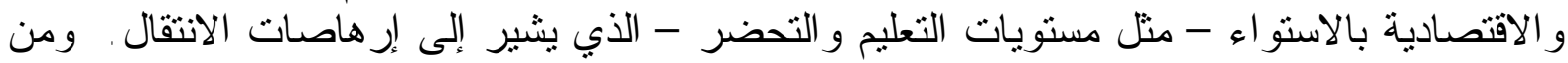

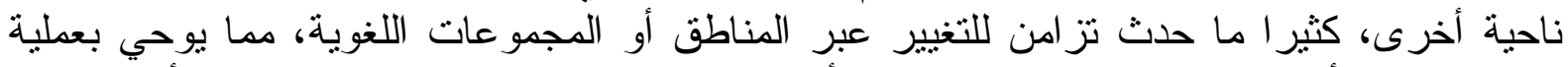

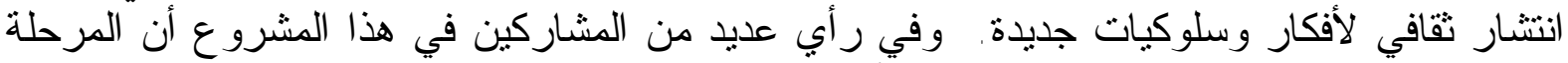

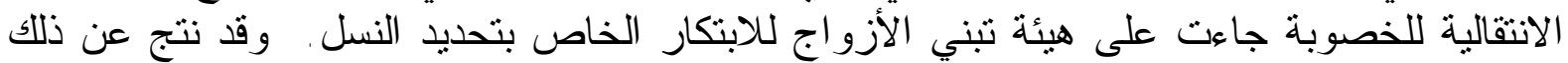

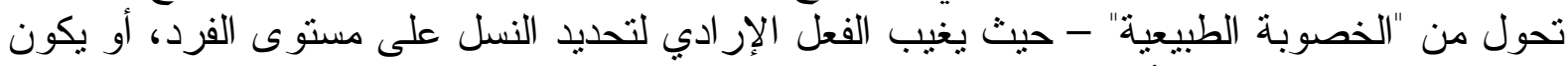

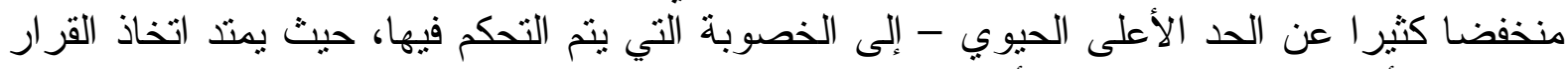

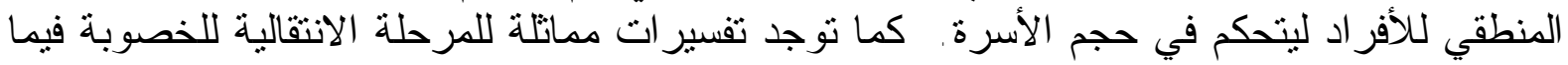

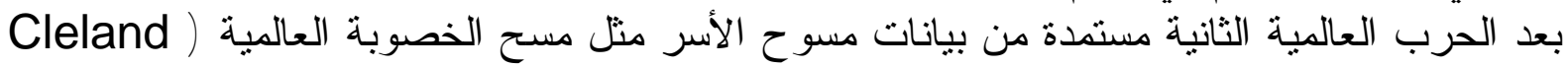

. (and Wilson 1987

وقد خضعت أيضا للمساعلة وجهة النظر التي ترى المرحلة الانتقالية للخصوبة باعتبار ها سلوك مبتكر

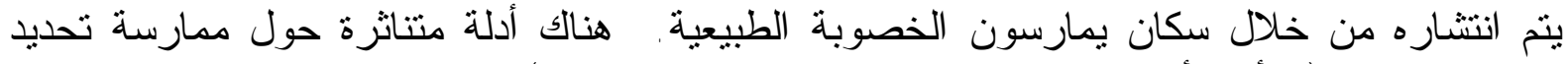

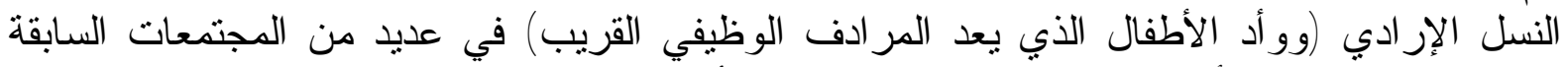

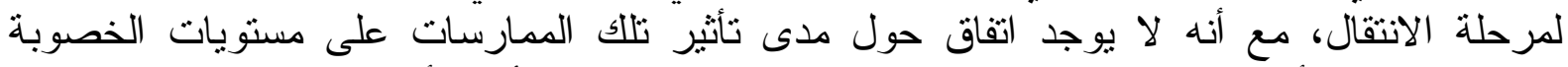

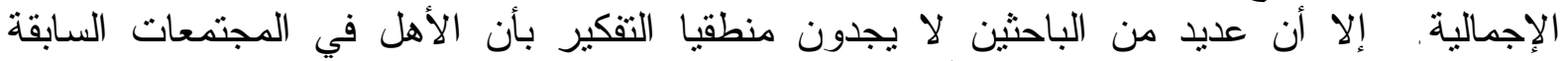

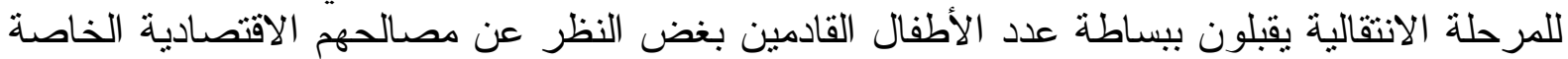

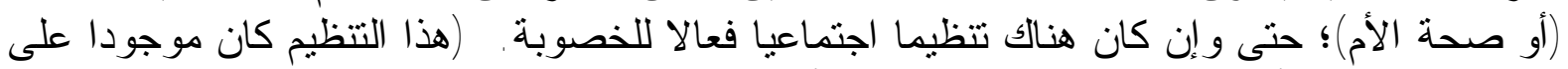

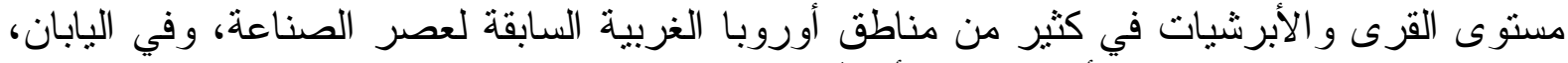

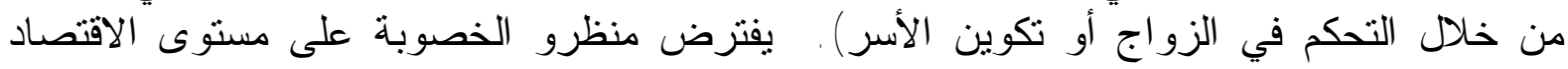

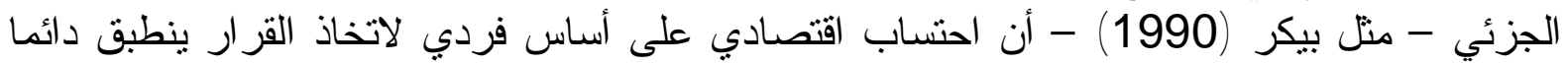

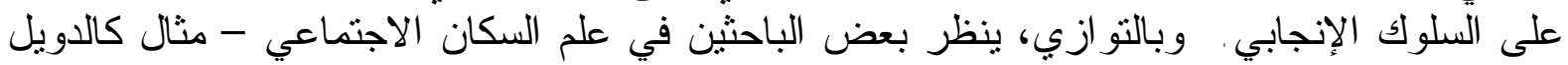

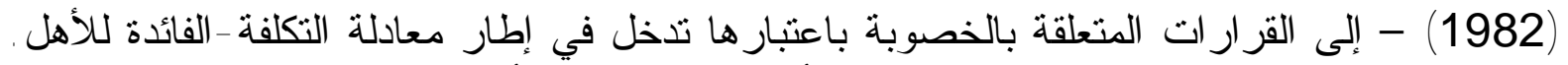

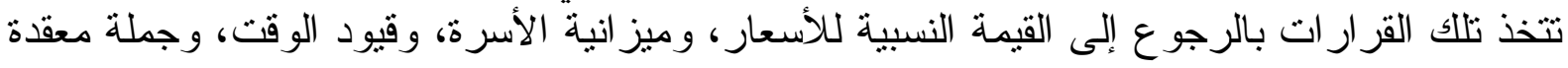

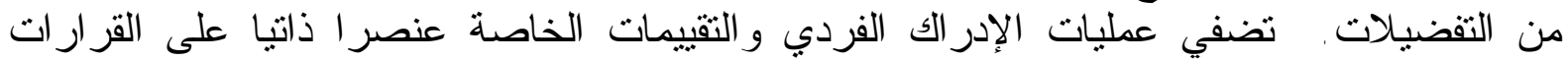
المتعلقة بالخصوبة، ولكن هذا لا يرقى إلى الوصول لإر ادة تخيلية حول المخرجات . لإن التيات 


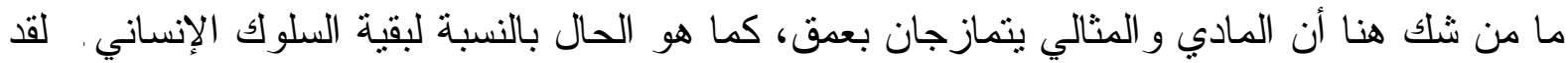
تم نشر المو اقف الجديدة من الإنجاب و المعرفة الأكثر شمو لا من خلال الشبكات الاجتماعية (يمكن

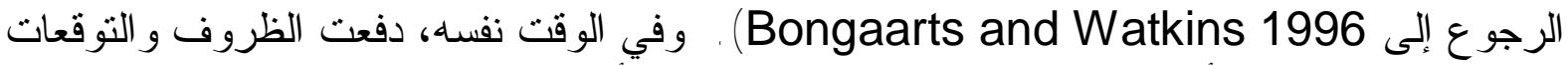
الاقتصادية المتغيرة الأسر إلى التحول من الاستثمار في رأس المال الاجتماعي إلى الاستثمار في

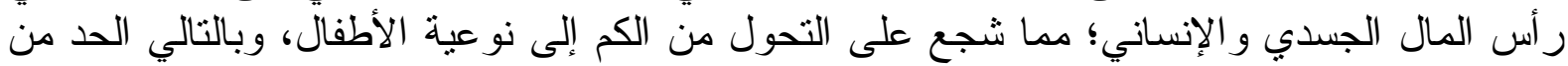

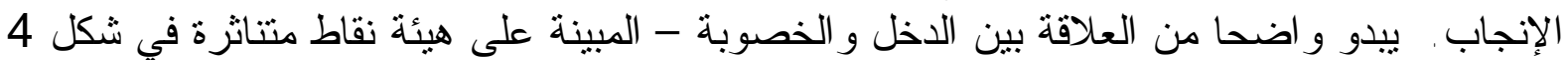

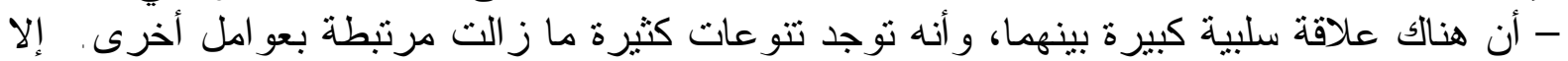
أن تلك العو امل الأخيرة تتضمن بالضرورة الجوانب المتعددة للتنمية التي تكون أسيرة التخدل المنخفض

\section{النهوض بالمر احل السكانية الاتتقالية}

كما تم الإشارة إليه سابقا، يلعب الانخفاض في معدلات كل من الوفيات و الخصوبة دورا إيجابيا

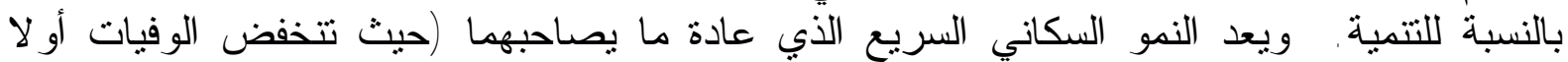

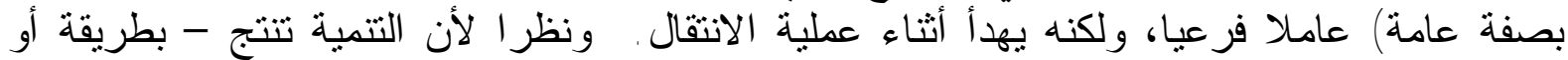

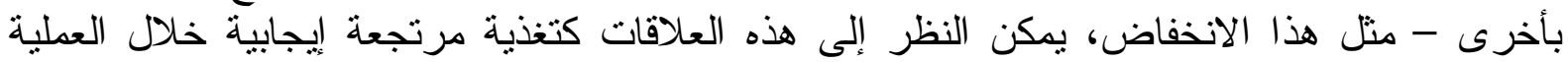

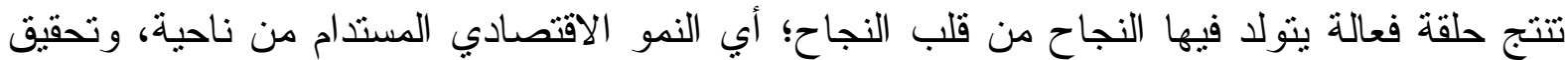
نظام ديموجر افي عصري من الناحية الأخرى. تعد مكونات التغيير السكاني وقود في النمط الإلي الإجمالي

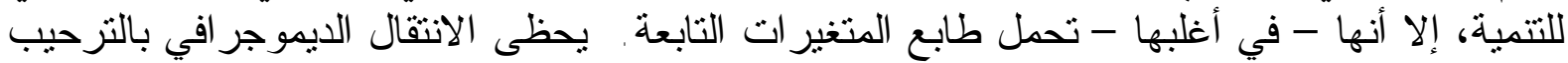

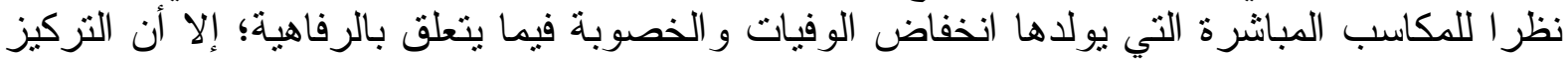

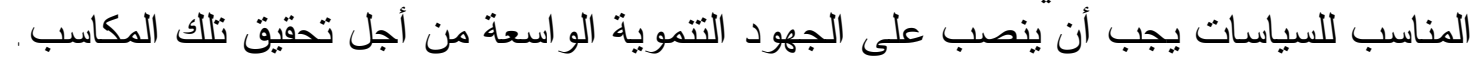

شكل 4: نقاط متتاثرة حول معدلات الخصوبة الإجمالية مقابل نصيب الفرد من الدخل بالنسبة لــ 137 بلد، 2000

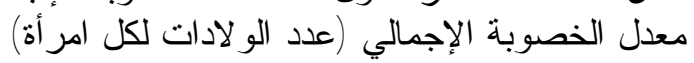
نصيب الفرد من الاخل (بالدو لار الدولي) 


\section{FIGURE 4}

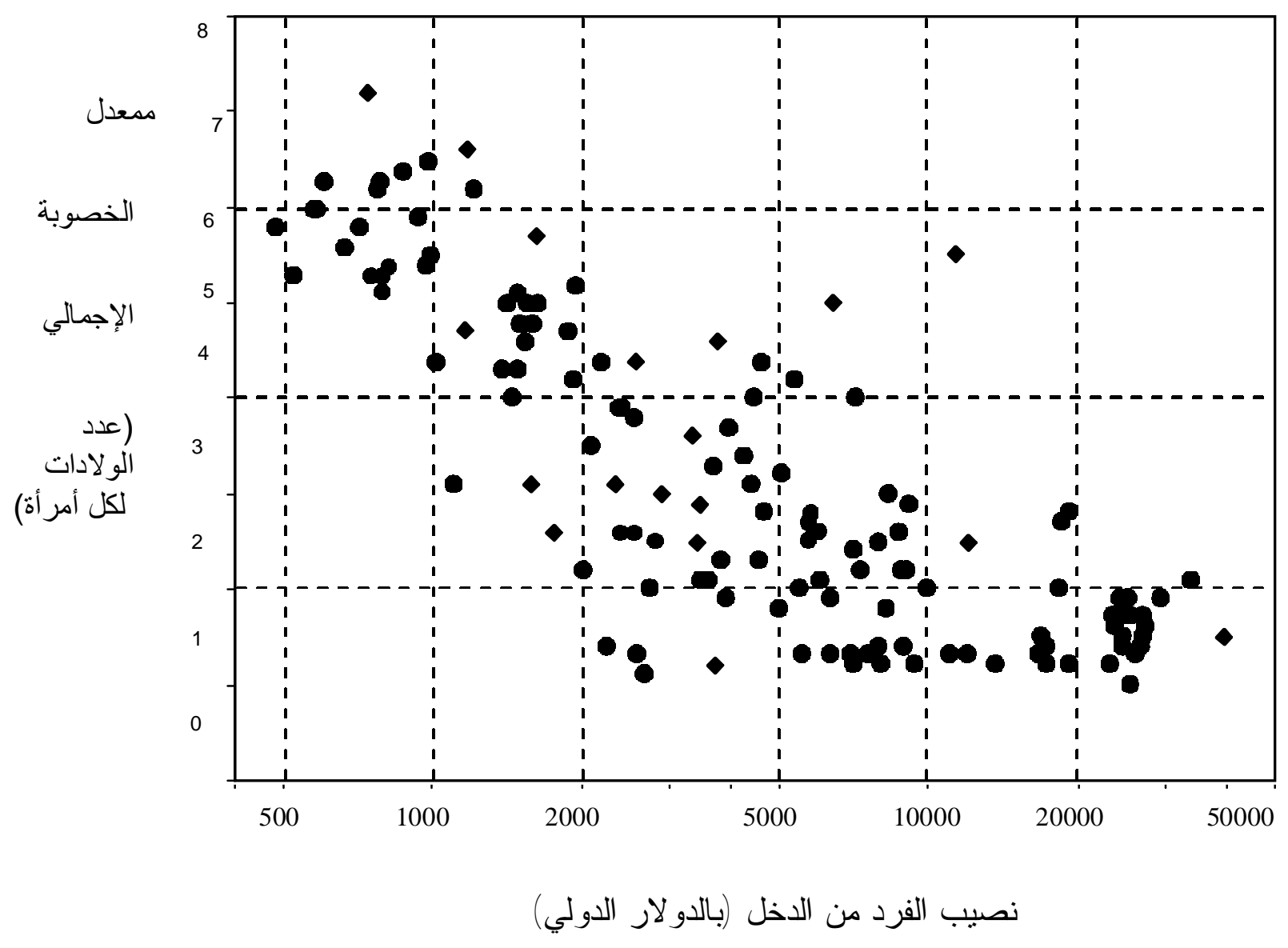

ملحوظة: الدخل يساوي القدرة الثرائية. تقع العربية السعودية في الركن العلوي الأيمن. مصدر البيانات: البنلك الدولي، مؤشر ات التنمية العالمية، 2002 


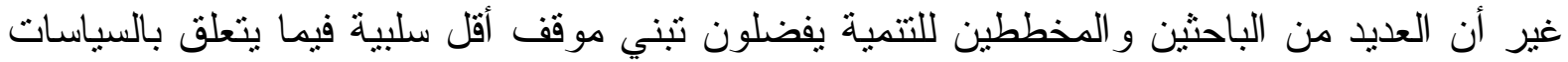

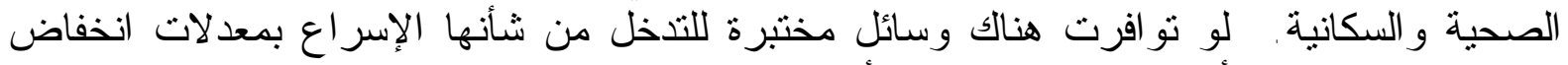
الوفيات و الخصوبة، لأمكن الحصول بطريقة أسر ع على المكاسب الخاصة بالئل بالرفاهية المباشرة و الجهود

كانت وسائل التدخل و اضحة بالنسبة للوفيات؛ يشير التحليل البيني - كالذي يتضمنه شكل 3 - أن آنار آلار

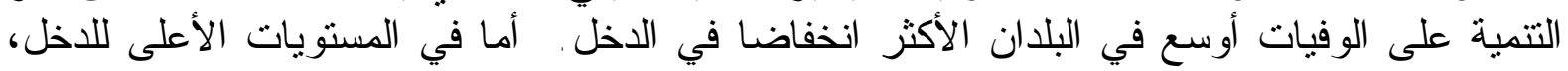

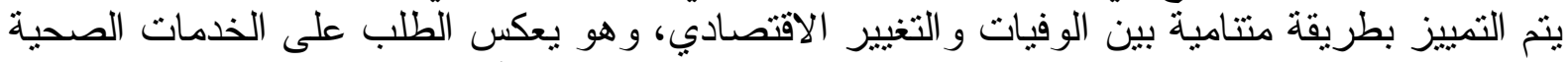

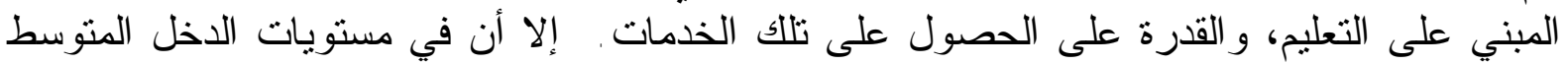

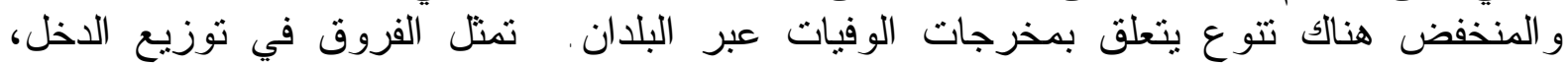

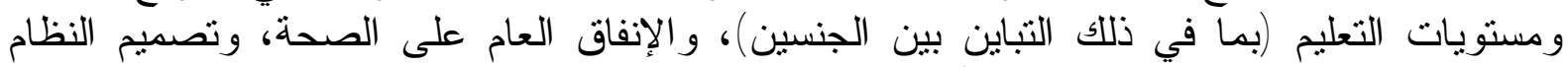

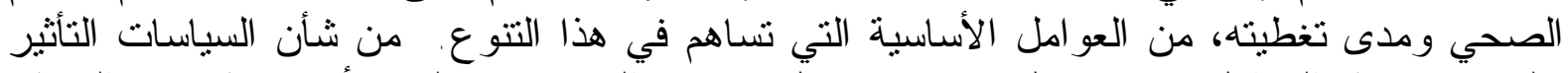

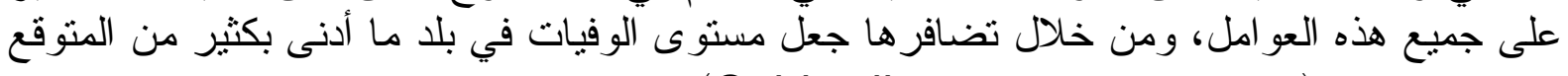

بناء على دخلها (يمكن الرجوع ون إلى خلى 1986 (Caldwell).

لقد دار الجدل في البحوث السكانية والتتموية حول الدرجة التي يمكن فيها أن نتأثر الخصوبة التئية

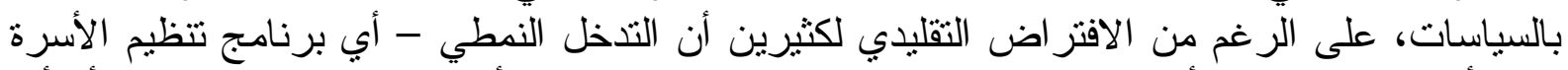

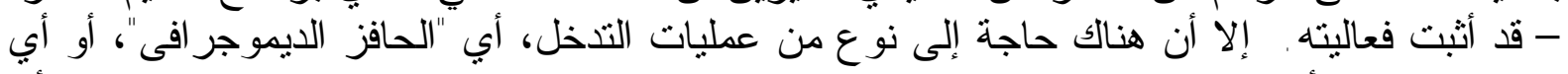

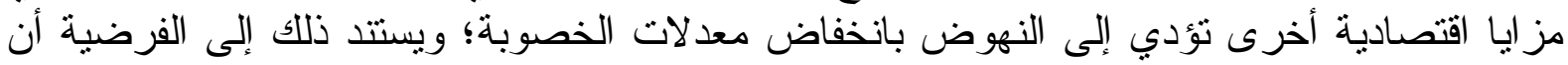

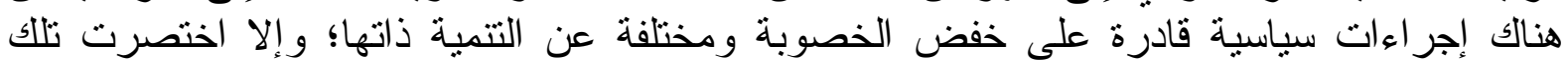
المز ايا في بعض التغذية المرتجعة الإيجابية الناتجة عن التنمية الناجحة.

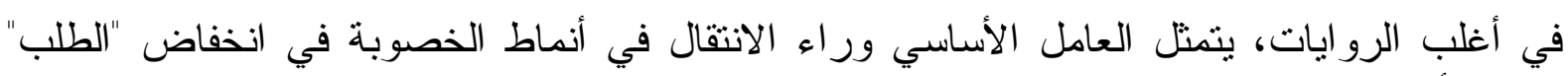

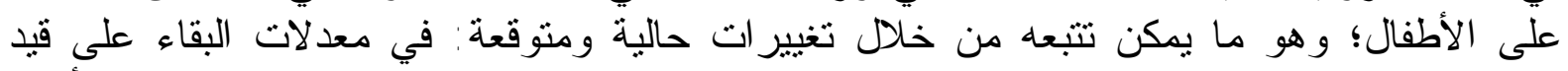

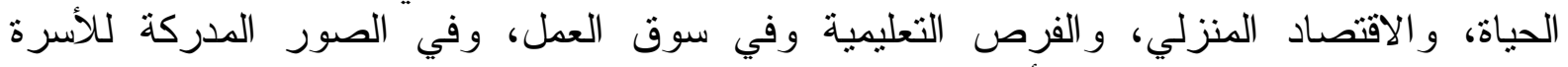

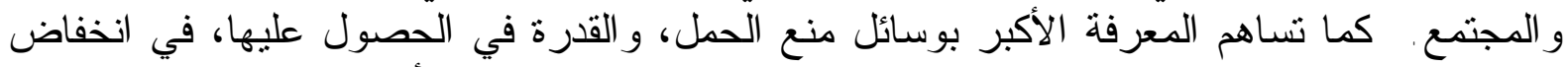

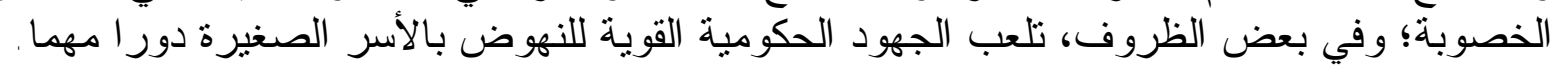

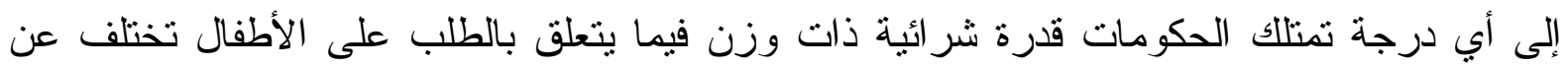

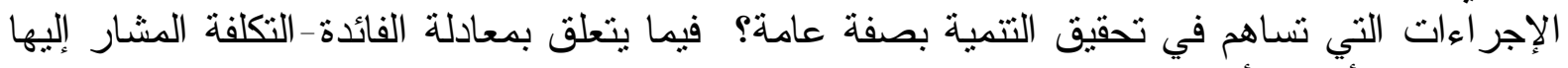

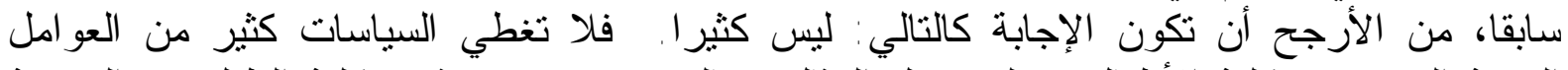

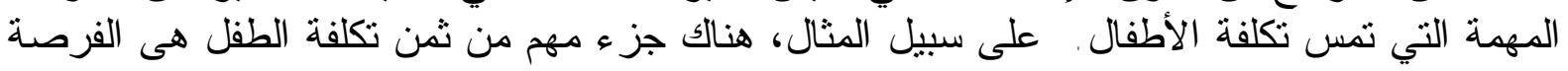

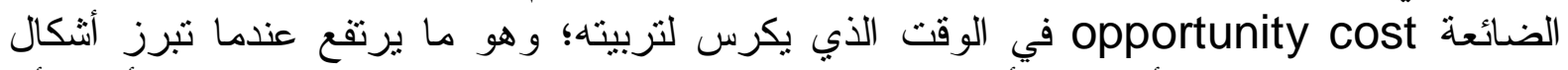

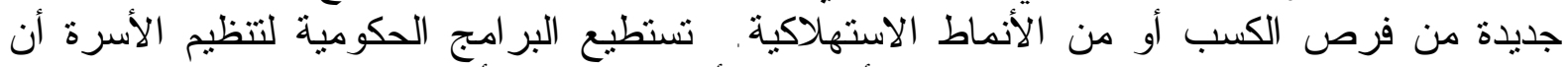

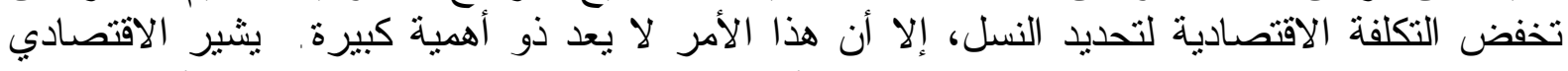
لاتت بريتشت Lant Pritchett

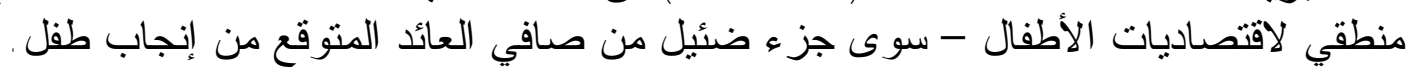

تعد التكاليف المباشرة للأطفال - خاصة في مجال الخدمات التعليمية و الصحية - كبيرة؛ وهي مهيأة

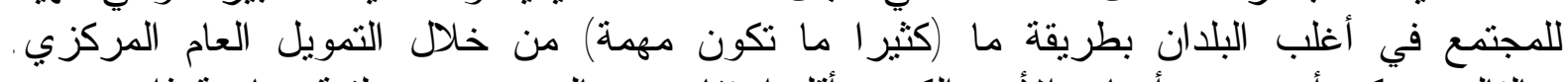

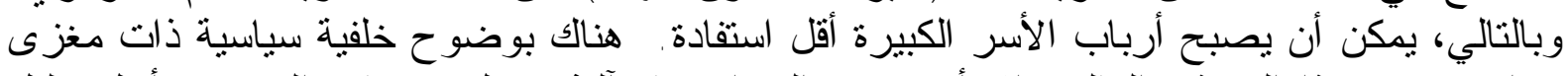
ور اء تصميم هذا النموذج المالي؛ إلا أنه يؤدي إلى استبعاد آلية تحمل مقومات القئ القوة من أجل تقليل 
الطلب على الأطفال. لقد جاء المنتج الفرعي لبر امج التكييف الهيكلي في قيام القادة الدوليين بمطالبة

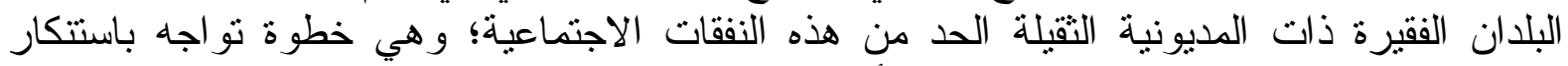
و اسع فيما يتعلق بالرفاهة، ولكن من الممكن أن تكون مؤثرة في الحد من الإنداءة الإنجاب.

خلافا للسياسات التي تؤثر على اقتصاديات الأطفال، مارست بعض البلدان في أوقات محددة ضغوطا

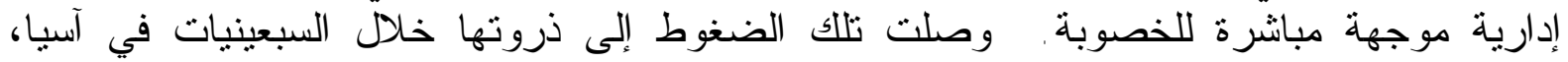

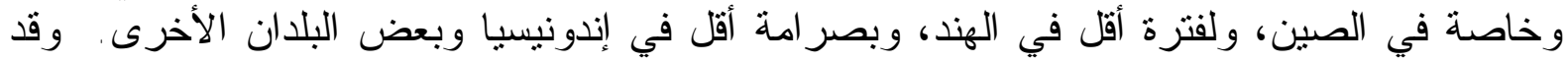

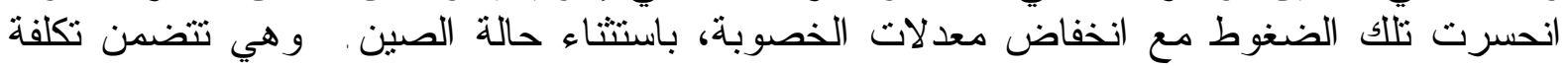
بشرية وسياسية.

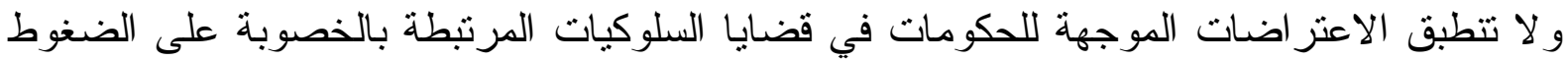

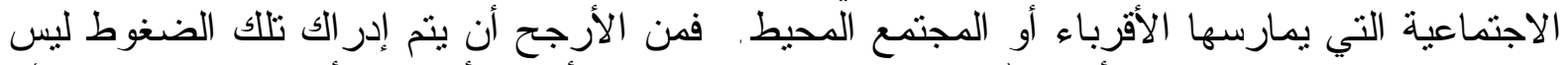

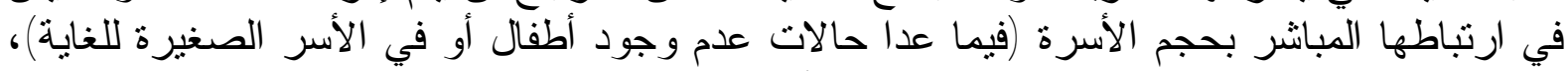

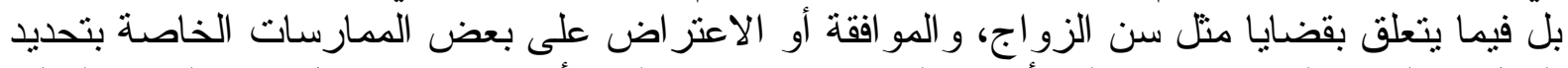

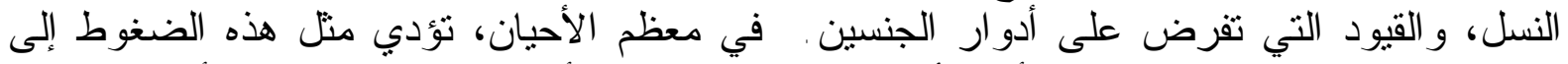

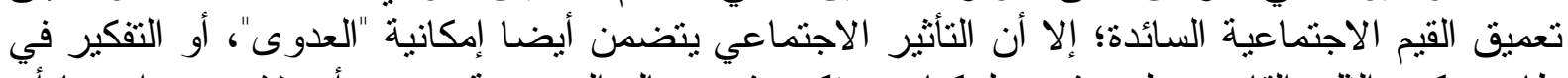

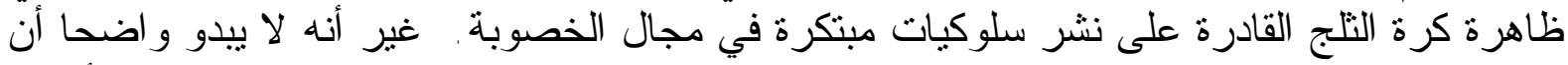

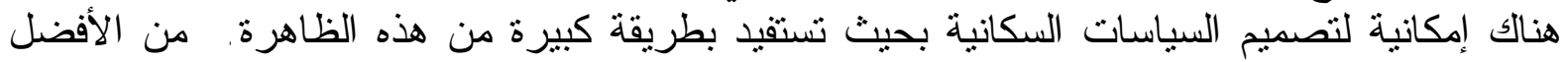

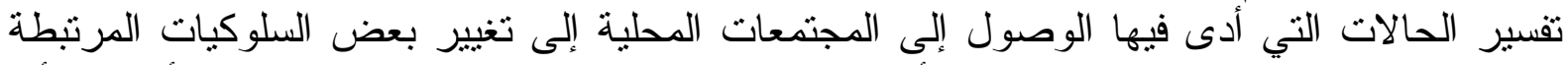

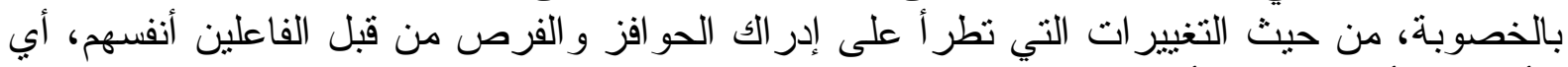

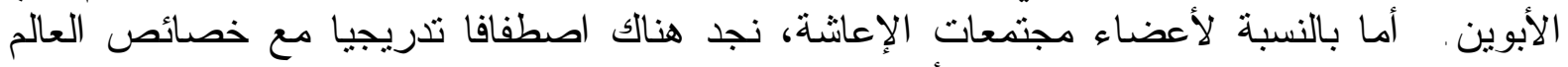

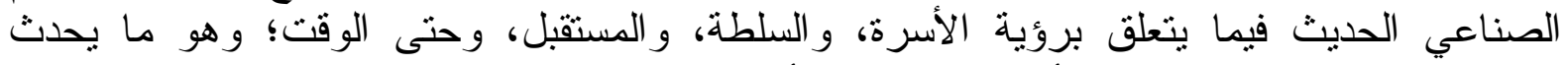
بطريقة شبه متبادلة، ولكن مع التأثير الاجتماعي كأحد قنو الات التوصيل .

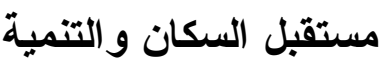

ييدو من الاتجاهات العالمية الاقتصادية والديموجر افية - في خطوطها العريضة - الملاحظة خلال

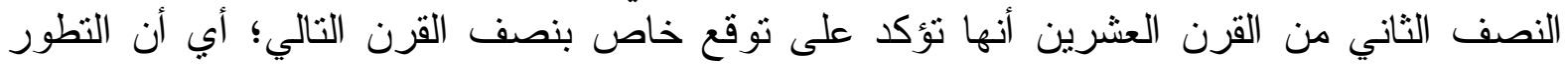

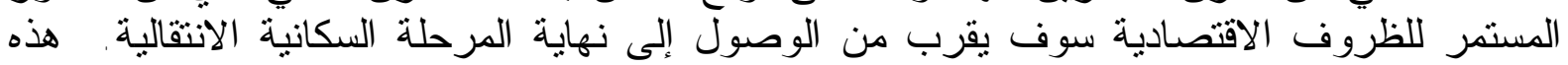

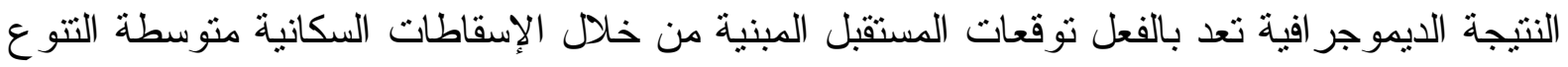

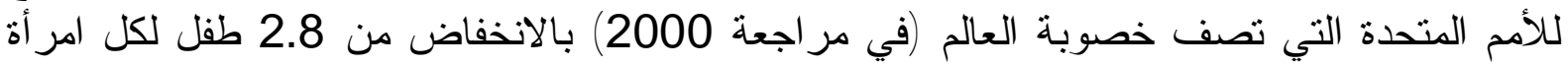

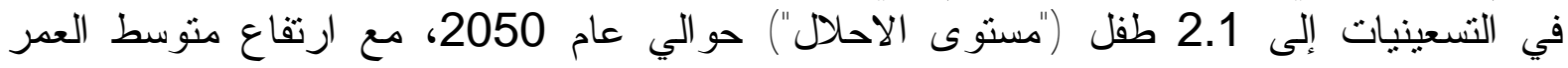

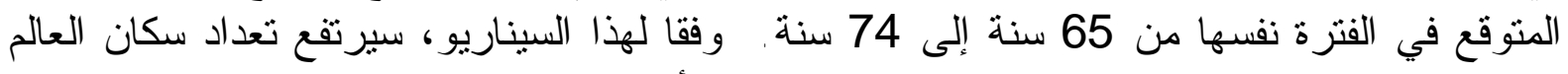

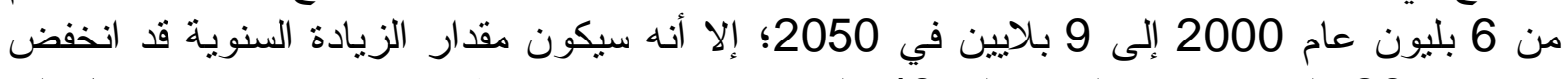

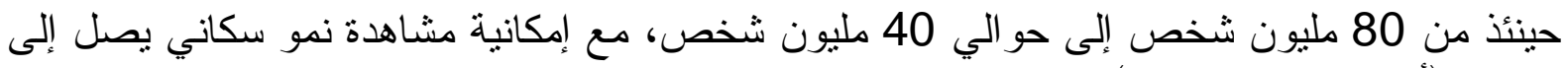

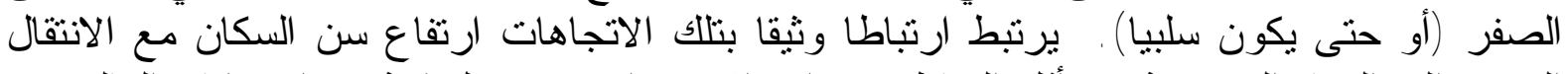

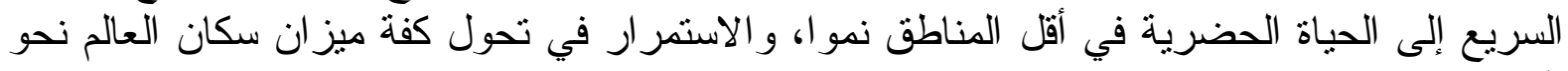

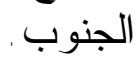

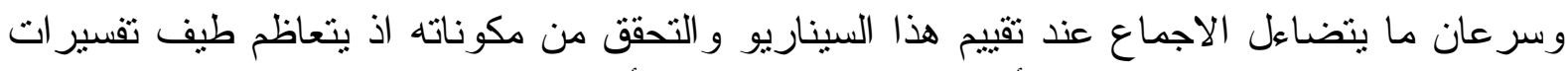
الخبرات السابقة عند النظر إلى الأمام. يقام لنا رينتارد أ. إيسترلين Richard A. Easterlin 


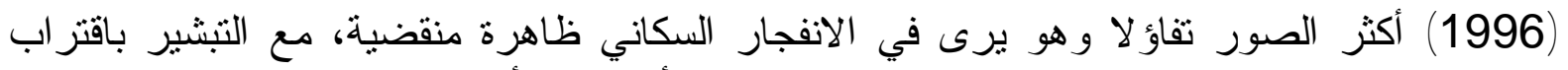

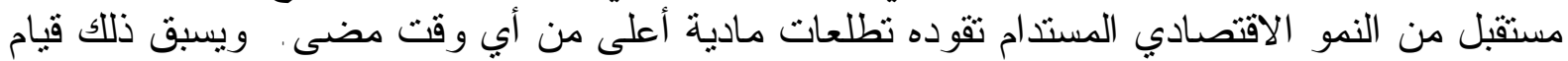

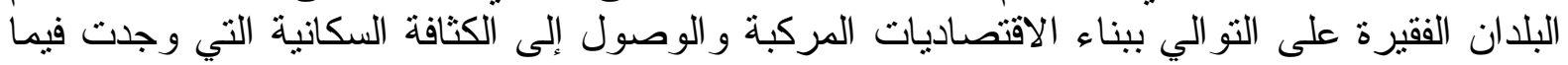

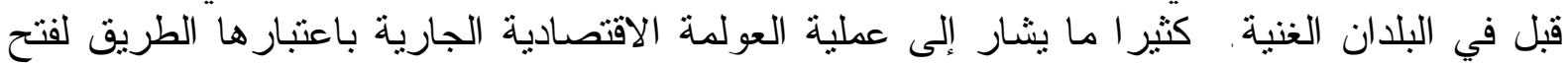

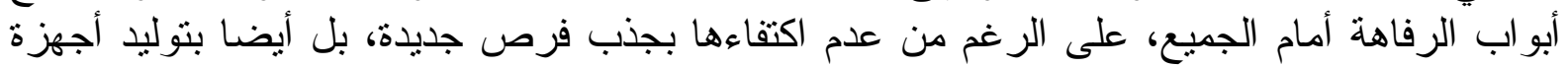
عامة ضعيفة.

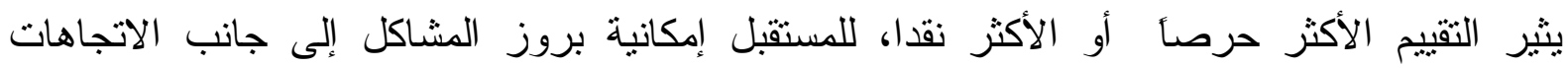

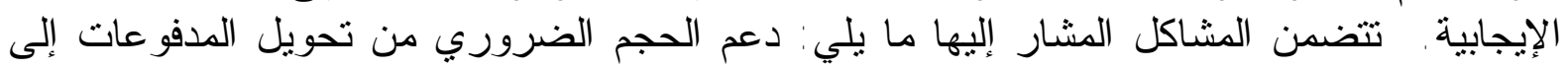

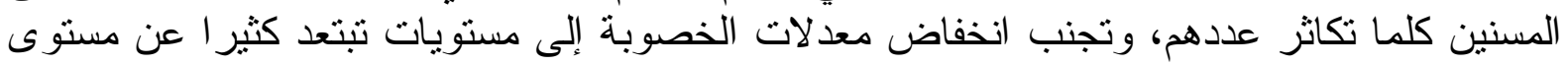

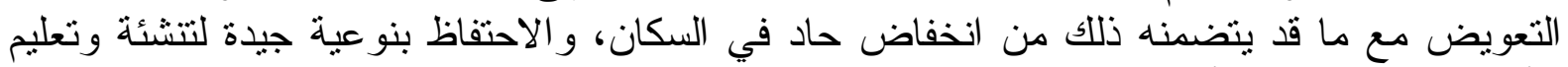

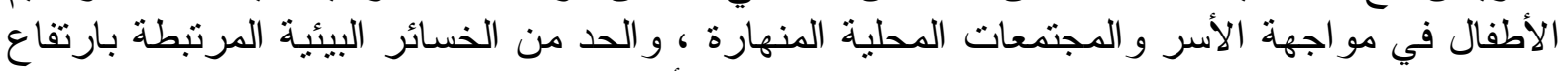

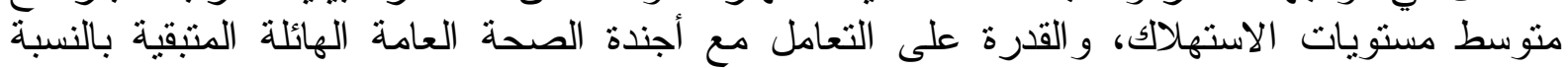

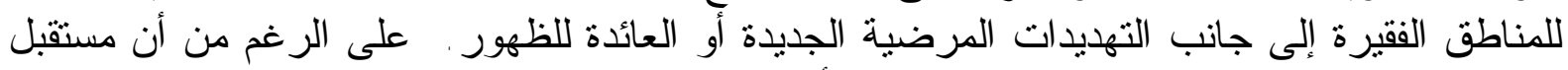

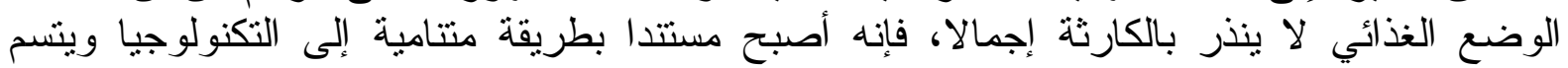

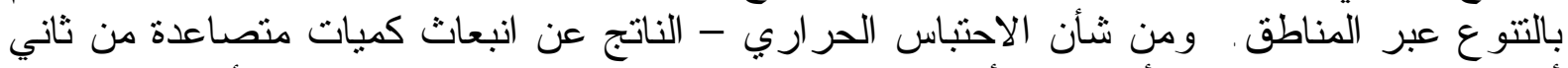

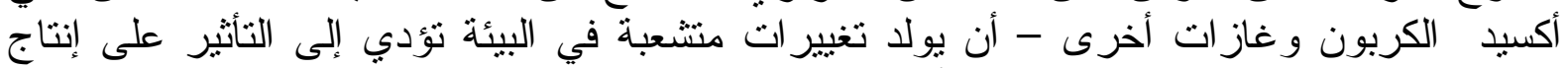

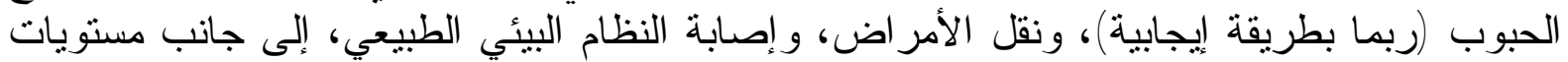

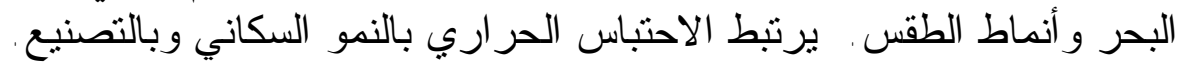

يمكن أن يكون للتغييرات السكانية تداعيات على المستوى السياسي؛ وبالتالي، تحمل التطورات

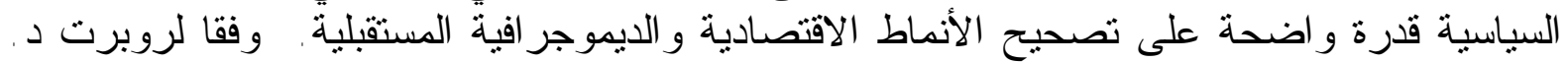
كابلان Robert D. Kaplan

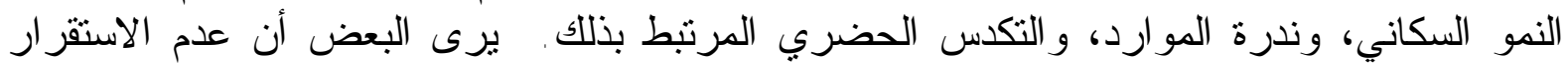

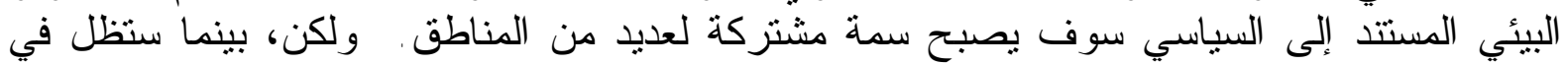

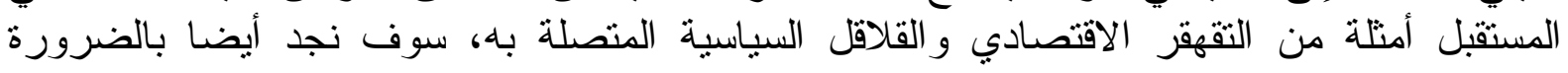
حالات من الثفاء وحتى من العودة إلى طريق النمو المستقر الإيجابي.

أما على المستوى الدولي، فإن التغييرات الهائلة الجارية بطريقة نسبية في حجم السكان عبر البلاندان

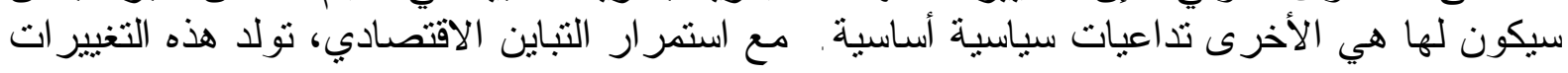

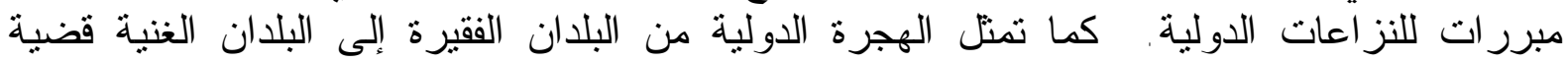

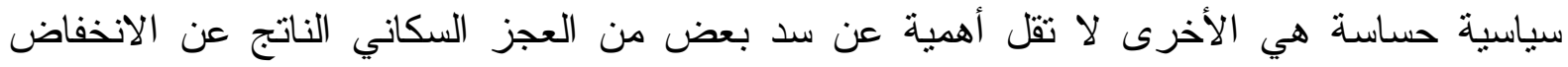

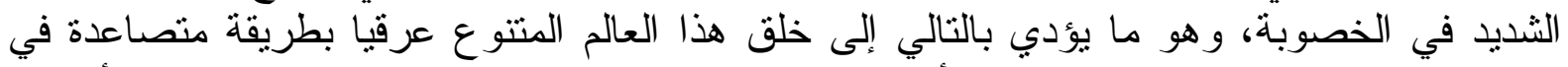

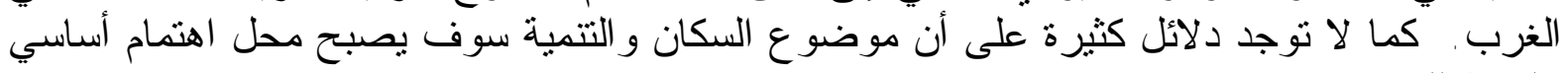
بالنسبة للمؤرخين . 